1 Enhanced Watershed Modeling by Incorporating Remotely Sensed Evapotranspiration

2

3

4

6

18

9

\title{
and Leaf Area Index
}

\author{
Sangchul Lee ${ }^{a^{*}}$, Gregory W. McCarty ${ }^{b}$, Glenn E. Moglen ${ }^{\mathrm{b}}$, Haw Yen ${ }^{\mathrm{c}}$, Fangni Lei ${ }^{\mathrm{b}}$, Martha \\ Anderson ${ }^{\mathrm{b}}$, Feng Gao ${ }^{\mathrm{b}}$, Wade Crow ${ }^{\mathrm{b}}$, In-Young Yeo ${ }^{\mathrm{d}}$, Liang Sun ${ }^{\mathrm{e}}$ \\ ${ }^{\text {a }}$ School of Environmental Engineering, University of Seoul, Dongdaemun-gu, Seoul 02504, \\ Republic of Korea
}

${ }^{\mathrm{b}}$ USDA-ARS, Hydrology and Remote Sensing Laboratory, Beltsville, MD 20705, United States

${ }^{\mathrm{c}}$ Blackland Research and Extension Center, Texas A\&M University, 720 East Blackland Road,

Temple, TX 76502, United States

${ }^{\mathrm{d}}$ School of Engineering, the University of Newcastle, Callaghan NSW 2308, Australia

${ }^{\mathrm{e}}$ Key Laboratory of Agricultural Remote Sensing, Ministry of Agriculture / Institute of Agricultural Resources and Regional Planning, Chinese Academy of Agricultural Sciences, Beijing 100081, China

\section{* Corresponding author}




\section{Abstract}

Remotely sensed evapotranspiration (RS-ET) products have been widely adopted as additional constraints on hydrologic modeling to enhance the model predictability while reducing predictive uncertainty. However, vegetation parameters, responsible for key time/space variation in evapotranspiration (ET), are often calibrated without the use of suitable constraints. Remotely sensed leaf area index (RS-LAI) products are increasingly available and provide an opportunity to assess vegetation dynamics and improve calibration of associated parameters. The goal of this study is to assess the Soil and Water Assessment Tool (SWAT) predictive uncertainty in estimates of ET using streamflow and two remotely sensed products (i.e., RS-ET and RS-LAI). We explore how the application of RS-ET and RS-LAI products contributes to 1) reducing the parameter uncertainty; 2) improving the model capacity to predict the spatial distribution of ET and LAI at the sub-watershed level; and 3) assessing the model predictions of ET and LAI at the basic modeling unit (i.e., the hydrologic response unit [HRU]) under the assumption that ET and LAI are related in croplands. Our results suggest that most of the parameter sets with acceptable performances for two constraints (i.e., streamflow and RS-ET; 12 parameter sets) are also acceptable for three constraints (i.e., streamflow, RS-ET, and RS-LAI; 11 parameter sets) at the watershed level. This finding is likely because both the ET simulation algorithm and the RS-ET products consider LAI as an input variable. Relative to the watershed-level assessment, the number of parameter sets that satisfactorily characterize spatial patterns of ET and LAI at the subwatershed level are reduced from 11 to 6 . Among the 11 parameter sets acceptable for three constraints (i.e., streamflow, RS-ET and RS-LAI) at the sub-watershed level, two parameter sets appear to provide high spatial and temporal consistency between ET and LAI at the HRU level. These results suggested that use of multiple remotely sensed products as model constraints enables 
48 model evaluations at finer scales - thereby constraining acceptable parameter sets and accurately

49 representing the spatial characteristics of hydrologic variables. As such, this study highlights the

50 potential of remotely sensed data to increase the predictability and utility of hydrologic models.

51

52 Keywords: Remotely sensed evapotranspiration (RS-ET); remotely sensed leaf area index (RS-

53 LAI); Soil and Water Assessment Tool (SWAT); predictive uncertainty

60

61 


\section{Introduction}

68

One major concern with regard to any hydrologic modeling exercise is predictive uncertainty. Although the reliability of simulated outcomes is assessed via model calibration and validation to some degree, predictive uncertainty always exists (Arnold et al., 2012; Yen et al., 2014a). A lack of observations is one of the primary uncertainty sources. The vast majority of hydrologic modeling studies depend solely on water quantity and/or quality measurements collected at the watershed outlet (Arnold et al., 2012; Gassman et al., 2014). To overcome predictive uncertainty resulting from data shortfalls, the use of so-called soft data (e.g., expert knowledge, literature, remotely sensed data and extensive field monitoring) has been suggested as an additional constraint (Arnold et al., 2015; Lee et al., 2019; Seibert and McDonnell, 2002; Yen et al., 2016).

Soft data have been used to better represent intra-watershed processes (i.e., the hydrologic processes that take place between the stream and upland areas; Yen et al., 2014a). The inclusion of soft data has been found to be efficient for constraining model parameter values, leading to a reduction of predictive uncertainty (Julich et al., 2012; Lee et al., 2019; Vaché and McDonnell, 2006).

The Soil and Water Assessment Tool (SWAT) is a semi-distributed hydrologic model that commonly encounters predictive uncertainty due to a lack of observations (Gassman et al., 2014). One way to address this problem is employing remotely sensed data into SWAT simulations, capturing plant growth (Strauch and Volk, 2013; Yeo et al., 2014), wetland inundation dynamics (Lee et al., 2019; Yeo et al., 2019), and soil moisture (Chen et al., 2011). Compared to in-situ measurements that require intensive labor and high cost, remotely sensed data have an advantage of providing measurements across landscapes for a long period, reducing the problem of data deficiency for hydrologic model operations (Jiang and Wang, 2019; Xu et al., 2014). The SWAT 
has been recently calibrated against remotely sensed evapotranspiration (referred to as RS-ET) products, leading to improved model predictions (Herman et al., 2018; Parajuli et al., 2018; Rajib et al., 2018; Wambura et al., 2018). Evapotranspiration (ET), defined as the sum of evaporation and transpiration fluxes, plays a critical role in water and energy cycling by transferring soil moisture to the atmosphere (Schlesinger and Jasechko, 2014). Thus, improved ET predictions can increase the overall accuracy of model outcomes.

A common use of RS-ET products as calibration data is to be used with streamflow to better constrain hydrologic parameters (Herman et al., 2018; Parajuli et al., 2018; Rajib et al., 2018; Wambura et al., 2018). Simultaneous use of streamflow and RS-ET products is capable of constraining parameter values, reducing predictive uncertainty (Herman et al., 2018; Parajuli et al., 2018; Rajib et al., 2018; Wambura et al., 2018). Wambura et al. (2018) showed the usefulness of RS-ET products in reducing the degree of equifinality (i.e., the tendency for different parameter sets [referred to as PARs hereafter] to produce equally acceptable model outputs; Beven, 2006). A study by Rajib et al. (2018) found substantial improvement in the modeled ET predictions by including vegetation parameters and the utility of RS-ET products in evaluating ET variations across a landscape. Thus, access to RS-ET products enables an assessment of model capacity to predict the spatial distribution of hydrologic variables (Becker et al., 2019; Rajib et al., 2018).

Root uptake of water, and subsequent transpiration from leaf area comprises a significant portion of total ET in vegetated area and thus its parameterization is crucial for ET simulations. However, previous studies have rarely included vegetation data for the calibration and validation 110 of ET simulations (Herman et al., 2018; Parajuli et al., 2018; Rajib et al., 2018; Wambura et al., 111 2018). Ha et al. (2018) applied remotely sensed ET and vegetation data into SWAT modeling, but

112 their study only focused on the usefulness of remotely sensed data for regions without streamflow 
113 observations. ET simulations without model calibration against vegetation data can be problematic

114 since SWAT estimates of ET may not accurately reflect the vegetation contribution. The leaf area

115 index (LAI), referred to as the projected leaf area over a unit of land, is an important vegetation

116 parameter closely related to vegetation transpiration (Bian et al., 2019; Gigante et al., 2009).

117 Several studies have emphasized that LAI should be taken into account for ET predictions due to

118 the strongly correlated relationship between ET and LAI (Wang et al., 2010; Yan et al., 2012). The

119 increased availability of remotely sensed LAI (referred to as RS-LAI) products provides an

120 opportunity to apply those data to hydrologic modeling studies (Andersen et al., 2002; Stisen et

121 al., 2008).

122 The primary goal of this study is to explore the hydrologic model predictive uncertainty in 123 estimating ET using daily streamflow, RS-ET, and RS-LAI products for a small watershed (221

$124 \mathrm{~km}^{2}$ ) within the Coastal Plain of the Chesapeake Bay Watershed (CBW). The hydrologic model

125 used in this study is the SWAT since remotely sensed data have been widely incorporated into the

126 model. We conducted a lumped parameterization at the watershed level using three constraints:

127 streamflow, RS-ET, and RS-LAI products. The PARs that result in acceptable streamflow and ET

128 simulations (referred to as "PARs-1", hereafter) were taken from all PARs explored for calibration.

129 In addition, the PARs with acceptable model performance measures for not only streamflow and

130 ET, but also LAI (referred to as "PARs-2", hereafter) were also extracted from all explored PARs.

131 Regarding the advantage of remotely sensed data, the spatial distribution of sub-watershed-level

132 ET and LAI simulations was also evaluated using the results from the PARs-2. We further

133 attempted to evaluate the model predictions at the smallest modeling unit, the Hydrologic

134 Response Unit (HRU), given the similar modeling behaviors of ET and LAI (Wang et al., 2010;

135 Yan et al., 2012). 
136 The specific objectives of this study are to: (i) compare the two PARs (i.e., PARs-1 and PARs-

137 2) along with their simulated outputs (e.g., streamflow, ET, and LAI) to explore the role of 138 vegetation constraints (i.e., RS-LAI products) for improving ET simulations and constraining 139 acceptable PARs; (ii) test whether those additional constraints (i.e., RS-ET and RS-LAI products)

140 are useful in identifying the PARs that well represent the spatial distribution of ET and LAI at 141 different spatial resolutions; and (iii) suggest the appropriate evaluation method for HRU-level 142 model predictions based on the relationship between ET and LAI.

\section{Materials and methods}

\subsection{Study area}

This study was conducted in the Tuckahoe Creek Watershed (TCW) upstream of the U.S. Geological Survey (USGS) gauge station \#01491500. The watershed is a sub-basin of the Choptank River watershed within the Coastal Plain of the CBW (Figure 1a). The Choptank River watershed has been the focus of intensive research (McCarty et al., 2008) led by the U.S. Department of Agriculture-Natural Resources Conservation Service (USDA-NRCS, Duriancik et al., 2008), and USDA-Agricultural Research Service (USDA-ARS, Baffaut et al., 2020). The TCW is predominantly covered by croplands (54\%), followed by forest (32.8\%), pasture (8.4\%), urban land $(4.2 \%)$ and water bodies $(0.6 \%$, Fig. 1b). The main crops in the watershed are corn, soybean, and winter wheat. Soils are evenly divided between well- (Hydrologic Soil Group (HSG) - A and B, $56 \%$ ) and poorly- (HSG - C and D\%, $44 \%$ ) drained soils (Fig. 1c). A detailed description of

156 HSGs can be found in Fig. 1. Based on long-term weather observations from three meteorological

157 stations operated by the National Climate Data Center (NCDC), National Oceanic and 
Atmospheric Administration (NOAA) (Fig. 1a), annual mean precipitation and temperature for the past 30 years $(1985-2014)$ are $1166 \mathrm{~mm}( \pm 228 \mathrm{~mm})$ and $13{ }^{\circ} \mathrm{C}\left( \pm 1{ }^{\circ} \mathrm{C}\right)$, respectively. In this region, precipitation is fairly uniform over the course of the year, but ET exhibits high seasonal variability (Fisher et al., 2010). Irrigation for corn and soybean production during the summer season has substantially increased in this region (Wolman, 2008), which can amplify water loss by ET during summer seasons. Water balance cycling in this region is greatly affected by the seasonal

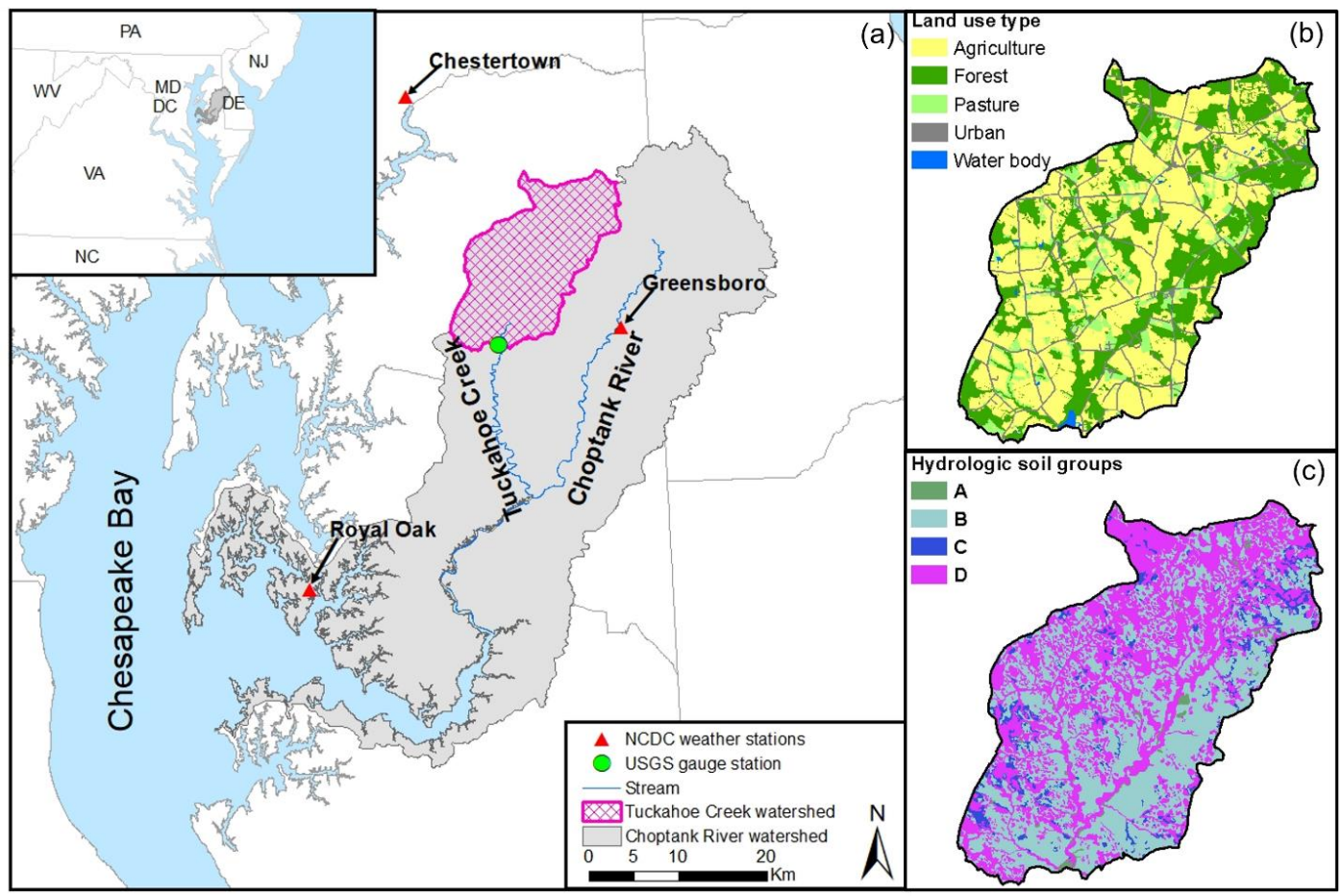

Fig. 1. Characteristics of the study area (Tuckahoe Creek Watershed): (a) location, (b) land use type, and (c) hydrologic soil groups (adapted from Lee et al. 2018a) Note: hydrologic soil groups (HSGs) are characterized as follows: Type A- well-drained soils with 7.6-11.4 $\mathrm{mm} \cdot \mathrm{hr}^{-1}$ water infiltration rate; B - moderately well-drained soils with $3.8-7.6 \mathrm{~mm} \cdot \mathrm{hr}^{-1}$; C - moderately poorly- 
drained soils with 1.3-3.8 $\mathrm{mm} \cdot \mathrm{hr}^{-1}$; and D - poorly-drained soils with $0-1.3 \mathrm{~mm} \cdot \mathrm{hr}^{-1}$ (Neitsch et al., 2011). HSG-A, B, C, and D account for $0.3,55.8,2.2$, and $41.7 \%$ of the TCW, respectively.

\subsection{Soil and Water Assessment Tool}

The SWAT model is a watershed-scale model designed for modeling the impacts of environmental and anthropogenic changes on hydrological processes within an agricultural watershed (Neitsch et al., 2011). The model partitions a given watershed into sub-watersheds and further into hydrologic response units (HRUs). Hydrologic variables are determined at the individual HRU level, and then outputs are combined at the sub-watershed and watershed level through channel processes (Neitsch et al., 2011). The cumulative water balance of each HRU is computed using Eq. 1:

$S W_{t}=S W_{0}+\sum_{i=1}^{t}\left(R_{\text {day }}-Q_{\text {surf }}-E_{a}-W_{\text {seep }}-Q_{g w}\right)$

where $S W_{t}$ is the final soil water content $\left(\mathrm{mm} \mathrm{H}_{2} \mathrm{O}\right), S W_{0}$ is the initial soil water content $(\mathrm{mm}$ $\mathrm{H}_{2} \mathrm{O}$ ), $t$ is the time (days), $R_{\text {day }}$ is the amount of precipitation on day $i\left(\mathrm{~mm} \mathrm{H}_{2} \mathrm{O}\right), Q_{\text {surf }}$ is the amount of surface runoff on day $i\left(\mathrm{~mm} \mathrm{H}_{2} \mathrm{O}\right), E_{a}$ is the amount of ET on day $i\left(\mathrm{~mm} \mathrm{H}_{2} \mathrm{O}\right), W_{\text {seep }}$ is the amount of percolation and bypass flow existing the soil profile bottom on day $i\left(\mathrm{~mm} \mathrm{H}_{2} \mathrm{O}\right)$, and $Q_{g w}$ is the amount of groundwater flow on day $i\left(\mathrm{~mm} \mathrm{H}_{2} \mathrm{O}\right)$.

The SWAT model first calculates potential ET (PET) and then estimates actual ET (AET) by subtracting several factors from PET. Three calculation methods for potential evapotranspiration (PET) are available in the SWAT model: Penman-Monteith, Priestley-Taylor, and Hargreaves (Neitsch et al., 2011). The Penman-Monteith method is expressed:

$$
\lambda E=\frac{\Delta \cdot\left(\mathrm{H}_{\mathrm{net}}-\mathrm{G}\right)+\rho_{\mathrm{air}} \cdot \mathrm{c}_{\mathrm{p}} \cdot\left[\mathrm{e}_{\mathrm{z}}^{0}-\mathrm{e}_{\mathrm{z}}\right] / \mathrm{r}_{\mathrm{a}}}{\Delta+\gamma \cdot\left(1+\mathrm{r}_{\mathrm{c}} / \mathrm{r}_{\mathrm{a}}\right)}
$$


194 where $\lambda \mathrm{E}$ is the latent heat of vaporization $\left(\mathrm{MJ} \mathrm{kg}^{-1}\right), E$ the depth rate evaporation $\left(\mathrm{mm} \mathrm{d}^{-1}\right), \Delta$ the slope of the saturation vapor pressure-temperature curve $\left(\mathrm{kPa}{ }^{\circ} \mathrm{C}^{-1}\right), H_{\text {net }}$ the net radiation (MJ $\left.\mathrm{m}^{-2} \mathrm{~d}^{-1}\right), \mathrm{G}$ the ground heat flux density $\left(\mathrm{MJ} \mathrm{m}^{-2} \mathrm{~d}^{-1}\right), \rho_{\text {air }}$ the air density $\left(\mathrm{kg} \mathrm{m}^{-3}\right), c_{p}$ the specific heat at constant pressure $\left(\mathrm{MJ} \mathrm{kg}^{-1}{ }^{\circ} \mathrm{C}^{-1}\right), e_{\mathrm{z}}^{0}$ the saturation vapor pressure of air at height $\mathrm{z}(\mathrm{kPa})$, $\mathrm{e}_{\mathrm{z}}$ the water vapor pressure of air at height $\mathrm{z}(\mathrm{kPa}), \gamma$ the psychrometric constant $\left(\mathrm{kPa}{ }^{\circ} \mathrm{C}^{-1}\right), \mathrm{r}_{\mathrm{c}}$ the plant canopy resistance $\left(\mathrm{s} \mathrm{m}^{-1}\right)$ and $\mathrm{r}_{\mathrm{a}}$ the diffusion resistance of the air layer (aerodynamic resistance) $\left(\mathrm{s} \mathrm{m}^{-1}\right)$.

After computing PET, AET is estimated in the SWAT. At first, rainfall captured by the plant canopy is evaporated. Then, the maximum amount of sublimation/soil evaporation is calculated and their actual amount is subsequently calculated. If a snow cover exits, sublimation will take place, but if not only soil evaporation is considered. Further details about the PenmanMonteith method and AET calculation are available in Neitsch et al. (2011).

In the SWAT, dynamic LAI estimates are generated as a function of the optimal leaf area development curve. This curve controls LAI growth by accumulated potential heat units. A daily potential heat unit is computed by the difference between daily average temperature and the base temperature. If the base temperature is greater than daily average temperature, a daily heat unit is zero. Once the LAI reaches its (vegetation type-specific) maximum value, the maximum LAI will be maintained until leaf senescence begins.

$$
L A I=L A I_{m x} \cdot \frac{\left(1-f r_{P H U}\right)}{\left(1-f r_{P H U, s e n}\right)}
$$

where LAI is the leaf area index for a given day, $L A I_{m x}$ is the maximum LAI, $f r_{P H U}$ is the fraction of potential accumulated heat units for the plant on a given day, $f r_{P H U, s e n}$ is the fraction of 
215 potential accumulated heat units where the senescence becomes the dominant growth process.

216 Please see Neitsch et al. (2011) for further details.

\subsection{Input and calibration data}

The SWAT model requires climate and geospatial data as input for simulations (Table 1).

Daily precipitation and temperature records from 2008 - 2014 were downloaded from the NOAA NCDC monitoring stations (Fig. 1a). Daily solar radiation, relative humidity, and wind speed were prepared using the SWAT model's built-in weather generator (Neitsch et al., 2011). Digital Elevation Model (DEM) data were collected by Maryland Department of Natural Resources (MDDNR) and the dataset was post-processed by USDA-ARS, Beltsville to use the DEM as input to the SWAT model. Soil map information corresponding to the study area was downloaded from Soil Survey Geographical Database (SSURGO). A land use map developed by Lee et al. (2016) was used, based on multiple geospatial sources listed in Table 1 (Lee et al., 2016). This map includes eight representative crop rotations (Table 2) with their locations determined by multi-year 
236 Table 1. List of SWAT model input and calibration data

\begin{tabular}{llll}
\hline Data Type & Source & Description & Year \\
\hline DEM & MD-DNR & LiDAR-based 10-meter resolution & 2006 \\
Land Use & USDA-NASS & Cropland Data Layer (CDL) & $2008-2012$ \\
& MRLC & National Land Cover Database (NLCD) & 2006 \\
& USDA-FSA- & $\begin{array}{l}\text { National Agricultural Imagery Program } \\
\text { digital Orthophoto quad imagery }\end{array}$ & 1998 \\
& APFO & TIGER road map & 2010 \\
& US Census & & \\
& Bureau & Soil Survey Geographical Database & 2012 \\
Soils & USDA-NRCS & (SSURGO) & $2008-2014$ \\
Climate & NCDC & Daily precipitation and temperature & $2008-2014$ \\
Streamflow & USGS & Monthly streamflow & $2010-2014$ \\
RS-ET & Sun et al. (2017) & Daily ET & $2010-2014$ \\
RS-LAI & & Daily LAI & \\
\hline
\end{tabular}

MRLC: Multi-Resolution Land Characteristics Consortium, USDA-FSA-APFO: USDA-Farm Service Agency-Aerial Photography Field Office, and TIGER: Topologically Integrated Geographic Encoding and Referencing.

Table 2. Eight representative cropland rotations used in the SWAT simulations.

\begin{tabular}{lllllllll}
\hline Type & 2008 & 2009 & 2010 & 2011 & 2012 & 2013 & 2014 & Proportion \\
\hline 1 & WW/Soyb & Corn & WW/Soyb & Corn & WW/Soyb & Corn & WW/Soyb & 14.5 \\
2 & Corn & WW/Soyb & Corn & WW/Soyb & Corn & WW/Soyb & Corn & 21.9 \\
3 & WW/Soyb & Corn & Soyb & Corn & WW/Soyb & Corn & Soyb & 7.7 \\
4 & Soyb & Corn & Soyb & Corn & Soyb & Corn & Soyb & 11.3 \\
5 & Corn & Soyb & Corn & Soyb & Corn & Soyb & Corn & 9.8 \\
6 & Corn & Corn & Corn & Corn & Corn & Corn & Corn & 17.1 \\
7 & Corn & Soyb & Soyb & Corn & Soyb & Soyb & Corn & 10.2 \\
8 & Soyb & Corn & Soyb & Soyb & Corn & Soyb & Soyb & 7.5 \\
Corn & 59 & 58 & 49 & 61 & 56 & 51 & 59 & 56 \\
Soyb & 41 & 42 & 51 & 39 & 44 & 49 & 41 & 44
\end{tabular}

WW/Soyb and Soyb indicate double crop winter wheat/soybean and soybean, respectively. The last column indicates the relative area (\%) of each crop rotation applied to croplands. The bottom two rows indicate the relative area $(\%)$ of corn and soybean fields resulting from different concurrent rotations. The shaded types $4-8$ are used for HRU-level assessment (see Section 2.5).

Daily streamflow records from 2010 to 2014 were obtained from USGS gauging station \#01491500 located at the outlet of TCW (Fig. 1a). Daily RS-ET products were generated from the regional Atmosphere-Land Exchange Inverse (ALEXI) model (Anderson et al., 1997, 2007) and associated flux spatial-temporal disaggregation scheme (DisALEXI) (Anderson et al., 2004). This 
251 multi-scale modeling system is based on the two-source energy balance model (Norman et al.,

252 1995), which uses remotely sensed land surface temperature (LST) observations to partition

253 available energy between latent and sensible heat fluxes from the soil and canopy components of

254 the scene. A data fusion algorithm can be used to fuse 30-m resolution/bi-weekly ET retrievals

255 from Landsat LST observations with 500-m/daily data from MODIS, which results in fused

256 datasets with both high spatial and temporal resolution (Anderson et al., 2018; Cammalleri et al.,

257 2013, 2014). Over the study area, 30-m daily RS-ET products from ALEXI/DisALEXI have been

258 well-validated against in-situ eddy covariance flux tower measurements with an average relative

259 error of $10 \%$ (Sun et al., 2017). RS-ET products used here cover the time period from January

2602010 to December 2014.

261 Daily LAI with a 500-m spatial resolution was generated from the MODIS Version 6 $262 \mathrm{LAI} / \mathrm{FPAR}$ products (MCD15A3H). MCD15A3H is a combined LAI product from two satellites

263 (Terra and Aqua) at 4-day temporal frequency. Daily LAI values were produced through two steps.

264 First, MODIS LAI quality control (QC) layers (FparLai_QC and FparExtra_QC) were used to 265 exclude LAI retrievals from partial clouds, cloud shadows, and dead detector. LAI retrievals from 266 the physical radiative-transfer model (main algorithm) and the empirical model (backup algorithm)

267 (Myneni et al., 2002) were separated. Second, the 4-day MODIS LAI data from the first step were 268 smoothed and interpolated to daily LAI values using the Savitzky-Golay (SG) filter approach. 269 Daily LAI values at 500-m spatial resolution from 2010 to 2014 were generated for this study. 
(a) ET at Feb. $1^{\text {th }}, 2012$

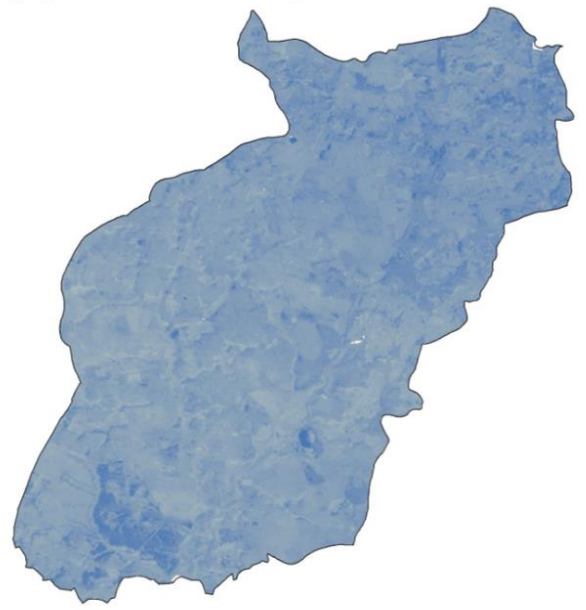

(c) LAl at Feb. $1^{\text {th }}, 2012$

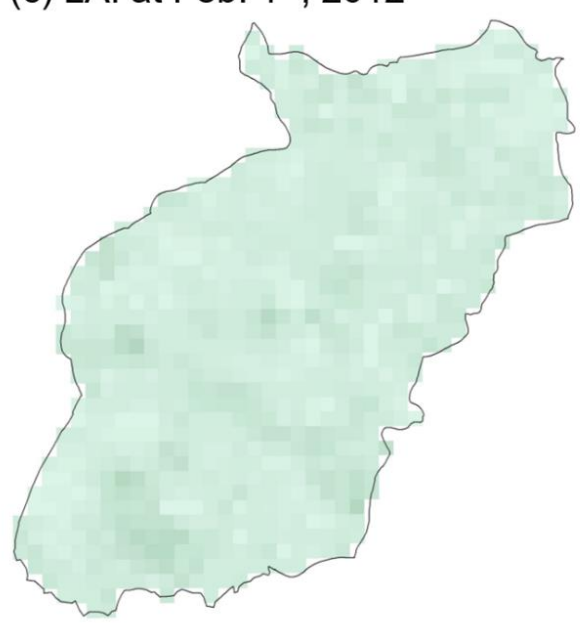

(b) ET at Aug. $1^{\text {th }}, 2012$

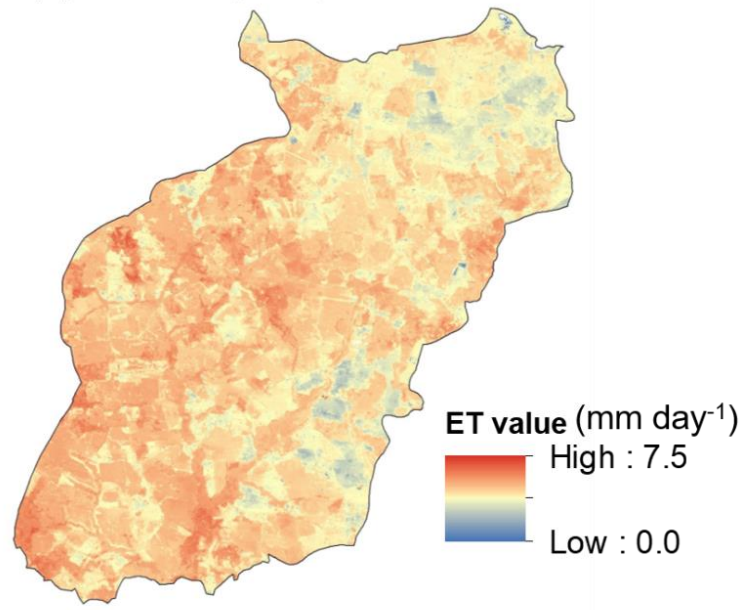

(d) LAl at Aug. $1^{\text {th }}, 2012$

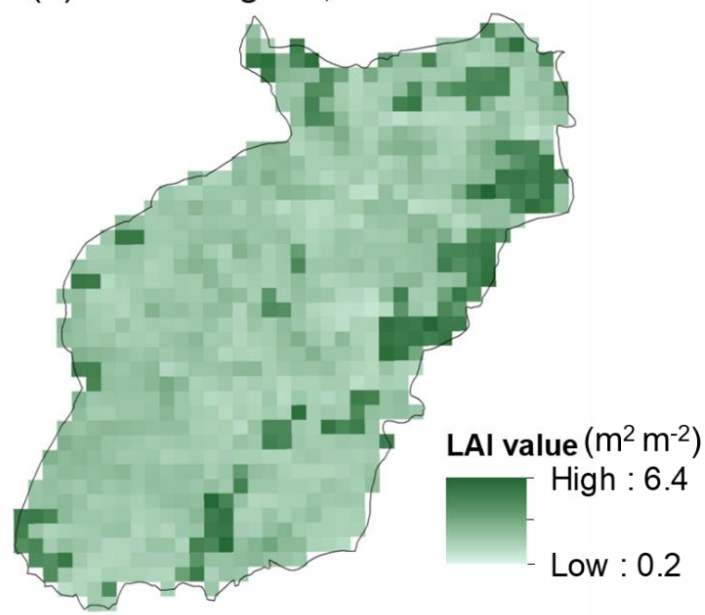

Fig. 2. Examples of RS-ET $\left(\mathrm{mm} \mathrm{day}^{-1}\right)$ and RS-LAI $\left(\mathrm{m}^{2} \mathrm{~m}^{-2}\right)$ used in this study.

\subsection{Model calibration and validation}

Model simulations were performed at a daily time step for seven years (2008 - 2014) given

275 the availability of RS-ET (2010 to 2014). The first two years (2008 - 2009) were used as a spin-

276 up period. Three years $(2010$ - 2012) were set aside for model calibration. Model validation was

277 executed for five years $(2010-2014)$ to consider seasonal and annual variability in hydrological 
278 processes (Rajib et al., 2018). This study used 13 hydrologic parameters shown to be sensitive to 279 streamflow in previous studies (Parajuli et al., 2013; Sexton et al., 2010; Yeo et al., 2014, Table 280 2). In addition to hydrologic parameters, 14 vegetation parameters were selected (Table 2). Only 281 corn and soybean parameters were calibrated since the distribution and rotation of the two crops 282 were well captured by the land use map used in this study and detailed practice schedules (e.g., the 283 application timing and amount of fertilizer, planting and harvesting timings) of the two crops were 284 well developed by local experts (Lee et al., 2016). Thus growth dynamics of corn and soybean were well depicted in our simulations. Double crop soybean was not calibrated as all information described above was made for summer crops. 3,000 PARs were prepared using the Latin Hypercube sampling (LHS) method. The LHS method divides a sampling space of individual parameters into multiple non-overlapping subspaces with equal probability (McKay et al., 2000). The LHS then generates one PAR by randomly selecting individual parameter values within each sub-space while forcing each sub-space to have only one value for each PAR (McKay et al., 2000). 
298 Table 3. The description, range, and sensitivity ranking of calibrated parameters

\begin{tabular}{|c|c|c|}
\hline Parameter & Description (units) & Range \\
\hline $\mathrm{CN}$ & SCS runoff curve number & $-20-20 \%$ \\
\hline GW_DELAY & Groundwater delay (days) & $0-100$ \\
\hline ALPHA_BF & Baseflow alpha factor $\left(\right.$ days $\left.^{-1}\right)$ & $0-1$ \\
\hline GWQMN & Threshold depth of water in the shallow aquifer required for return flow to occur $\left(\mathrm{mm} \mathrm{H}_{2} \mathrm{O}\right)$ & $0-5000$ \\
\hline GW_REVAP & Groundwater "revap" coefficient & $0.02-0.2$ \\
\hline REVAPMN & Threshold depth of water in the shallow aquifer for "revap" to occur $\left(\mathrm{mm} \mathrm{H}_{2} \mathrm{O}\right)$ & $0-500$ \\
\hline SOL_AWC & Available water capacity of the soil layer $\left(\mathrm{mm} \mathrm{H}_{2} \mathrm{O} \cdot \mathrm{mm} \mathrm{soil}^{-1}\right)$ & $-50-50 \%$ \\
\hline CH_K2 & Effective hydraulic conductivity in the main channel alluvium & $0-150$ \\
\hline CH_N2 & Manning's " $\mathrm{n}$ " value for the tributary channels & $0.01-0.3$ \\
\hline SURLAG & Surface runoff lag coefficient & $0.5-24$ \\
\hline ESCO & Soil evaporation compensation factor & $0-1$ \\
\hline EPCO & Plant uptake compensation factor & $0-1$ \\
\hline CANMX & Maximum canopy storage $\left(\mathrm{mm} \mathrm{H}_{2} \mathrm{O}\right)$ & $0-1$ \\
\hline BIO_E (corn) & Radiation use efficiency in ambient $\mathrm{CO}_{2}$ & $14-54$ \\
\hline HVSTI (corn) & Harvest index for optimal growing conditions & $0.4-0.7$ \\
\hline BLAI (corn) & Maximum potential leaf area index & $4-8$ \\
\hline FRGRW1 (corn) & $\begin{array}{l}\text { Fraction of the plant growing season of total potential heat units corresponding to the first point on the leaf } \\
\text { area development curve }\end{array}$ & $0-0.4$ \\
\hline FRGRW2 (corn) & $\begin{array}{l}\text { Fraction of the plant growing season of total potential heat units corresponding to the second point on the leaf } \\
\text { area development curve }\end{array}$ & $0.4-1$ \\
\hline LAIMX1 (corn) & Fraction of the maximum leaf area index corresponding to the first point on the leaf area development curve & $0-0.4$ \\
\hline LAIMX2 (corn) & Fraction of the maximum leaf area index corresponding to the second point & $0.4-1$ \\
\hline BIO_E (soybean) & Radiation use efficiency in ambient $\mathrm{CO}_{2}$ & $14-54$ \\
\hline $\begin{array}{l}\text { HVSTI } \\
\text { (soybean) }\end{array}$ & Harvest index for optimal growing conditions & $0.4-0.7$ \\
\hline BLAI (soybean) & Maximum potential leaf area index & $4-8$ \\
\hline $\begin{array}{l}\text { FRGRW1 } \\
\text { (soybean) }\end{array}$ & $\begin{array}{l}\text { Fraction of the plant growing season of total potential heat units } \\
\text { corresponding to the first point on the leaf area development curve }\end{array}$ & $0-0.4$ \\
\hline $\begin{array}{l}\text { FRGRW2 } \\
\text { (soybean) }\end{array}$ & $\begin{array}{l}\text { Fraction of the plant growing season of total potential heat units } \\
\text { corresponding to the second point on the leaf area development curve }\end{array}$ & $0.4-1$ \\
\hline $\begin{array}{l}\text { LAIMX1 } \\
\text { (soybean) }\end{array}$ & $\begin{array}{l}\text { Fraction of the maximum leaf area index corresponding to the first } \\
\text { point on the leaf area development curve }\end{array}$ & $0-0.4$ \\
\hline $\begin{array}{l}\text { LAIMX2 } \\
\text { (soybean) }\end{array}$ & $\begin{array}{l}\text { Fraction of the maximum leaf area index corresponding to the second } \\
\text { point }\end{array}$ & $0.4-1$ \\
\hline
\end{tabular}
point

Note: Parameter values for PARs-1 and PARs-2 are shown in the supplementary material Table S2. Squared Error (MSE) to provide a combined measure of relative importance of correlation, bias and variability for hydrological modelling (Gupta et al., 2009). KGE values range from $-\infty$ to 1 , 
where $r$ indicates the Pearson product-moment correlation coefficient, $\sigma_{s} / \sigma_{o}$ and $\mu_{s} / \mu_{o}$ indicate variability ratio and bias between simulations and observations, respectively, $\sigma$ and $\mu$ indicate the standard deviation and mean of the variables, respectively. The subscripts, $s$ and $o$, indicate simulations and observations, respectively. KGE was computed using the "hydroGOF" package of the R program (Zambrano, 2017). This study defined the acceptable daily model performance measure as streamflow $(\mathrm{KGE} \geq 0.65)$ and $\mathrm{ET}(\mathrm{KGE} \geq 0.55)$. These criteria thresholds have been viewed as "satisfactory" in previous studies (Becker et al., 2019; Poméon et al., 2018; Rajib et al., 2018; Wallace et al., 2018). The ET criterion was directly applied to define the acceptable LAI criterion (KGE $\geq 0.55)$ as vegetation dynamics indicated by LAI substantially accounts for ET.

\subsection{The spatial distribution of ET and LAI at the sub-watershed level}

We compared simulated ET and LAI with RS-ET and RS-LAI products, respectively, at the sub-watershed level. RS-ET and RS-LAI products were discretized by the sub-watershed boundary generated from the ArcSWAT interface using the input DEM (Winchell et al., 2007). The TCW includes 19 sub-watersheds, and except for one sub-watershed smaller than the LAI pixel size $\left(0.25 \mathrm{~km}^{2}\right), 18$ sub-watersheds with sizes ranging from $2.55-31.19 \mathrm{~km}^{2}$ were used for the subwatershed-level spatial evaluation. This evaluation was conducted using simulations from PARs2 that show acceptable daily performance for streamflow, ET and LAI. We computed KGE values for ET and LAI for individual sub-watersheds and computed the median KGE values. The PARs with the median KGE values equal or greater than 0.55 for both ET and LAI were considered to 
The PARs not meeting these criteria were viewed as unable to capture the spatial distribution of

330 ET and LAI at the sub-watershed level although they showed acceptable performance at the

331 watershed level. We used the evaluation results to further assess the degree of equifinality.

\subsection{Consistency between ET and LAI at the HRU-level}

Relative to the sub-watersheds, the size and configuration of HRUs are small and irregularly shaped, which often constrain the use of remotely sensed data for the HRU-level evaluation. Becker et al. (2019) pointed out that remotely sensed data are limited for a watershed dominated by small croplands, and the HRU-level calibration requires substantial computer resources as well as data processing to use remotely sensed data. Rather than directly using remotely sensed data to assess HRU-level simulation, we explored the relationship between simulated outputs at the HRU level. The simulated outputs accepted for upper-level spatial units (i.e., the results from PARs-2) were adopted in the HRU-level assessment. The relationship of two simulated ET and LAI at the HRU level was viewed as the assessment criteria based on the assumption that the dynamics of ET and LAI are similar in croplands and thus a well-calibrated model can show the correlations between ET and LAI. The comparison of simulated ET and LAI at the cropland HRUs can be a way to test whether PARs suitable for the (sub)watershed-level can also capture HRU-level processes.

This hypothesis was tested on five different types (4 - 8) of croplands (see Table 2) where 348 corn and soybean are cultivated during summer growing seasons (May to October) from 2010 to 3492014 (Fig. 3). Croplands with double crop winter wheat/soybean were excluded in this analysis 350 because of inaccurate crop information during non-summer growing seasons. The results from 

seasons for individual cropland types (Fig. 3). For the spatial consistency, 5-year summer growing season averages of ET and LAI at individual HRUs within individual cropland types. Then, ET and LAI were compared individually for each cropland type (Fig. 3). Temporal and spatial consistency were also evaluated for individual PARs-2. The degree of consistency was quantified using the coefficient of determination $\left(\mathrm{R}^{2}\right)$.

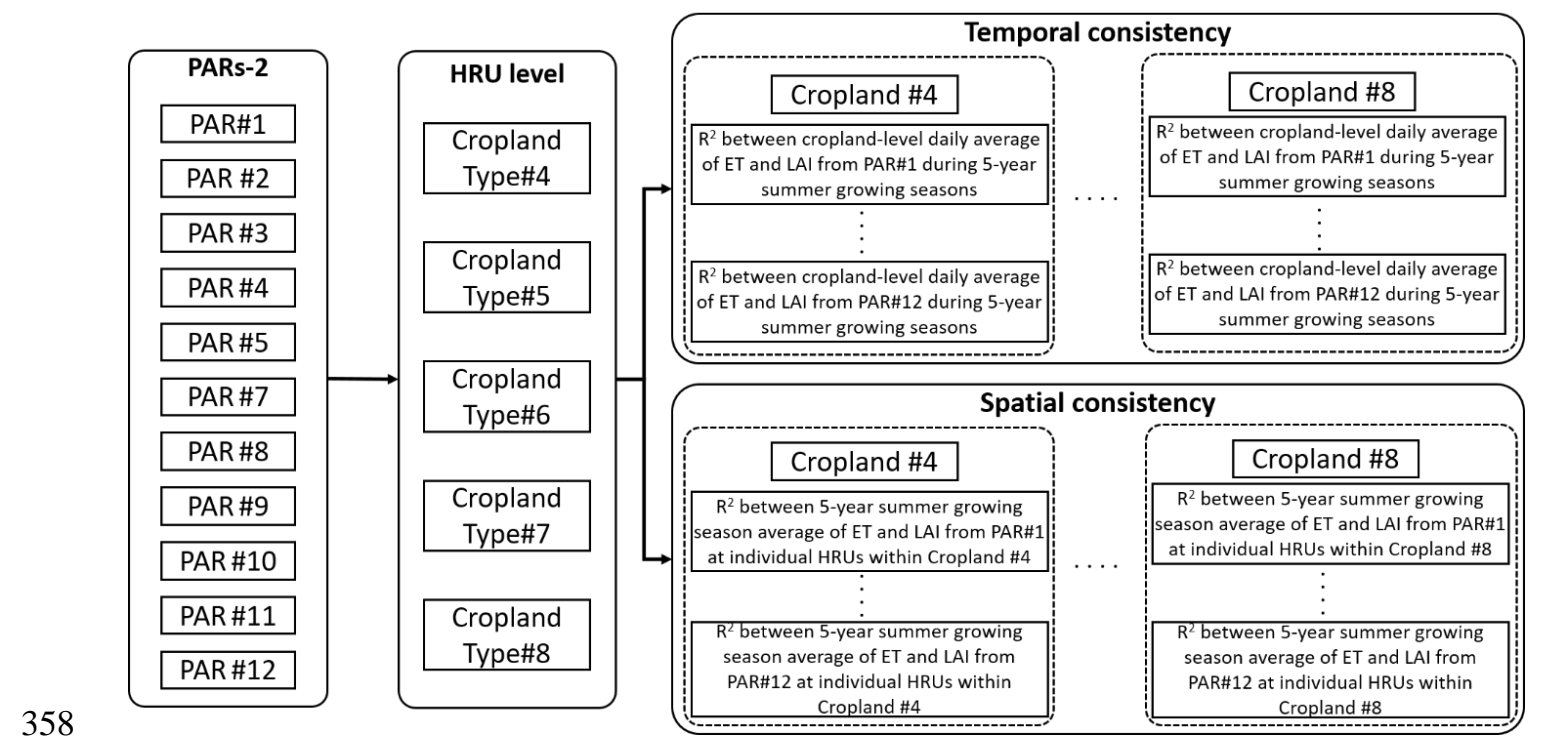

359 Fig. 3. Diagram of the HRU-level assessment 

spatial and temporal consistency between ET and LAI, respectively. The Pareto frontiers (i.e., PAR) frequently shown in five cropland types were chosen as the optimal PAR for watershed- and field-level evaluation.

\section{Results and discussions}

3.1. Impacts of vegetation data on ET predictions and predictive uncertainty at the

Among 3,000 PARs, there were 12 PARs with acceptable model performances for streamflow and RS-ET (i.e., PARs-1). The observed streamflow, RS-ET, and RS-LAI were plotted with simulation results from two parameter sets (\#7 and \#9) with the high KGE values during the calibration period (Fig. 4). The visual comparisons of the other ten PARs are available in the supplementary material Figs. S1 - S3. The ranges of KGE values for PARs-1 were $0.65-0.87$ $(0.65-0.83)$ for streamflow and $0.58-0.60(0.55-0.57)$ for RS-ET during calibration (and validation) periods (Table 4). 11 PARs (PARs-2) simultaneously satisfied model performance thresholds for streamflow, RS-ET, and RS-LAI (Table 4). The model performance measures for PARs-2 were $0.65-0.87(0.65-0.83)$ for streamflow, $0.58-0.60(0.55-0.57)$ for RS-ET, and $0.66-0.70(0.66-0.71)$ for RS-LAI during calibration (and validation) periods. 

results.

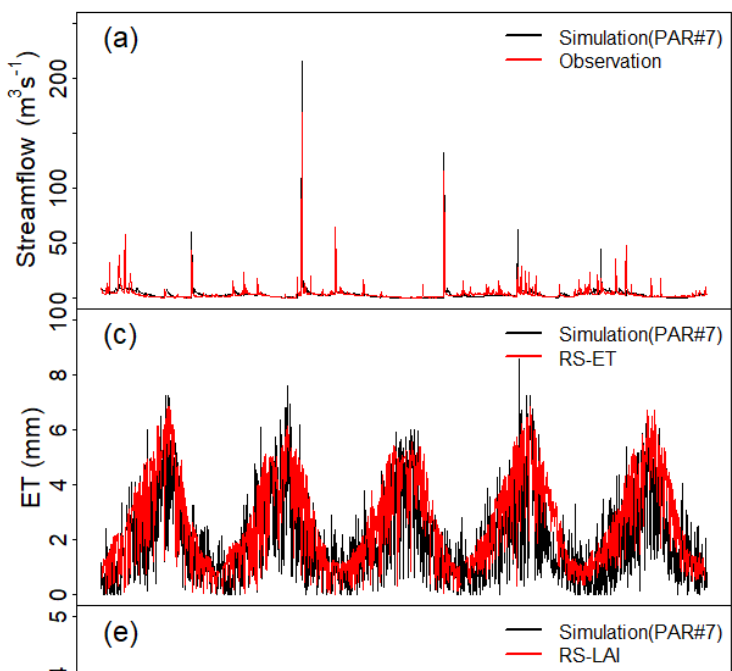

(b) $\quad$ - Simulation(PAR\#9)
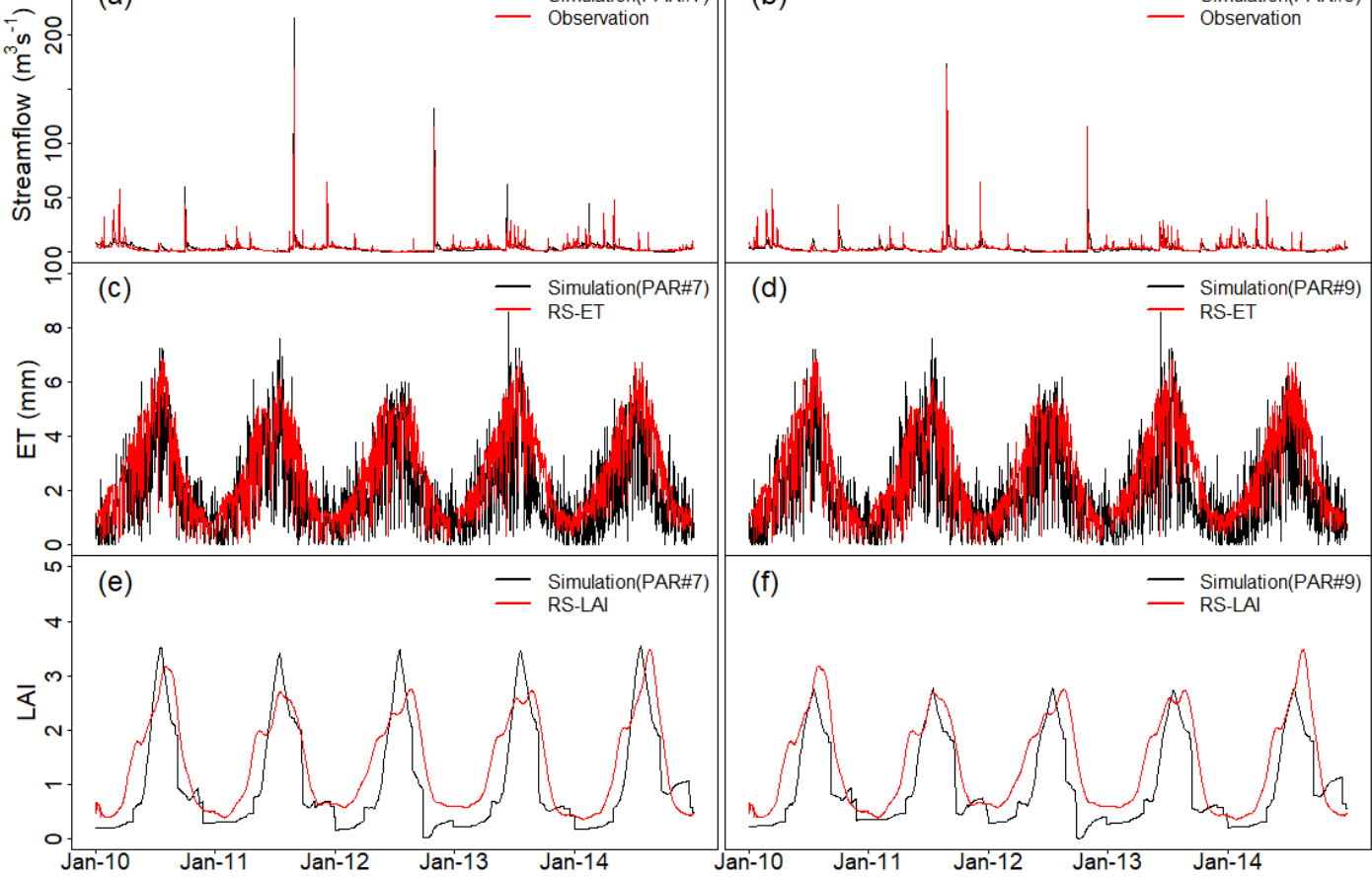

Fig. 4. Comparison of daily simulations with observed streamflow, watershed-level RS-ET, and RS-LAI during the simulation period from 2010 to 2014 . The unit of LAI is $\mathrm{m}^{2} \cdot \mathrm{m}^{-2}$. The simulations results from PAR \#7 (a, c, and e) and \#9 (b, d, and f) are only shown in Fig. 3. Results for the other ten acceptable PARs are provided in the supplementary material Figs. S1 - S3. 
400 Table 4. Performance measures (KGE value) for daily streamflow, RS-ET, and RS-LAI

401

\begin{tabular}{llllllllllllll}
\hline PAR & & 1 & 2 & 3 & 4 & 5 & 6 & 7 & 8 & 9 & 10 & 11 & 12 \\
\hline \multirow{2}{*}{ Streamflow Cal. } & 0.67 & 0.65 & 0.83 & 0.67 & 0.74 & 0.71 & 0.87 & 0.79 & 0.80 & 0.75 & 0.66 & 0.67 \\
& Val. & 0.68 & 0.67 & 0.81 & 0.69 & 0.69 & 0.70 & 0.83 & 0.75 & 0.74 & 0.75 & 0.69 & 0.65 \\
\multirow{2}{*}{ ET } & Cal. & 0.59 & 0.59 & 0.59 & 0.59 & 0.59 & 0.58 & 0.60 & 0.59 & 0.60 & 0.59 & 0.58 & 0.59 \\
& Val. & 0.57 & 0.56 & 0.56 & 0.57 & 0.57 & 0.55 & 0.57 & 0.57 & 0.57 & 0.57 & 0.55 & 0.56 \\
\multirow{2}{*}{ LAI } & Cal. & 0.67 & 0.63 & 0.61 & 0.66 & 0.70 & 0.42 & 0.65 & 0.61 & 0.66 & 0.63 & 0.65 & 0.65 \\
& Val. & 0.69 & 0.67 & 0.66 & 0.67 & 0.71 & 0.49 & 0.68 & 0.66 & 0.66 & 0.66 & 0.67 & 0.69 \\
\hline
\end{tabular}

402

Note: The column with the gray background is the parameter set not included in PARs-2.

Simulated streamflow did not capture observed peak flows over the simulation period (Fig. 4ab and Fig. S1). This may be because the precipitation data collected at the weather stations do not fully represent the spatial variations of meteorological conditions across the entire study site. Localized variations in precipitation have frequently been observed at this study area, which might further contribute to the underestimation of peak streamflow (Lee et al., 2016; Yeo et al., 2014). ET and LAI results showed strong seasonal trends with high values during the summer season (May to October) and low values during the winter season (November to April), which agreed with an earlier study by Fisher et al. (2010) and local tower measurements (Sun et al., 2017). Warm temperatures and plant growth led to peak ET and LAI values during the summer season.

The underestimation of ET simulations (Fig. 4cd and Fig. S2) can be attributed to a number of possible factors. A previous study also reported the ET simulations were lower than remotely sensed ET (Odusanya et al., 2019). The underestimated ET for this study is likely attributable to the exclusion of irrigation practices in our simulations due to inadequate associated information while the thermal ET remote sensing approach directly captures the impact of irrigation on ET (Hain et al., 2015). A previous study found that improved ET simulation resulted from the inclusion of irrigation practices in simulations (Chen et al., 2017). In addition, forested areas 
accounts for $33 \%$ of our study site, and these areas were simulated using default growth

420 parameters due to the absence of adequate forest growth data for calibration. Depressional

421 wetlands, abundant in forested areas of this region, are likely to lose water via ET at rates larger

422 than captured by the SWAT model. Therefore, the ET module in the forested settings may be an

423 additional factor leading to the underestimated model ET (Fig. 4ef and Fig. S3). Winter cover

424 crops are widely implemented in this region to reduce nutrient loads and those crops are shown to

425 increase the wintertime vegetation index (Hively et al., 2020). The omission of winter cover crops

426 from our simulation resulted in low LAI relative to RS-LAI.

\subsection{Comparing model results with RS-ET and RS-LAI at the sub-watershed level}

Sub-watershed-level KGE values were calculated for daily ET and LAI in Fig. 4. The median KGE values for ET ranged from 0.52 to 0.56 (Fig. 5a). Increased KGE values were observed for LAI (0.60 - 0.65, Fig. 5b) relative to ET. Only six PARs-2 (\#1, \#2, \#3, \#7, \#8 and \#12) were found to exceed the sub-watershed-level ET criteria ( $\mathrm{KGE} \geq 0.55$ ). In compliance with the watershedlevel result, the PAR\#7 case is associated with high KGE values for ET (0.57) and LAI (0.63) at the sub-watershed level (Fig. 5 a and c). However, the PAR\#9 case, exhibiting high KGE values at the watershed level, narrowly failed to meet the sub-watershed-level criteria for ET (0.54, Fig. $6 \mathrm{~b}$ and d). The number of acceptable PARs decreased from 11 (PARs-2) to six, which can suggest that the sub-watershed-level assessment help to identify the PARs that satisfactorily characterize internal processes at a finer spatial level. This finding supports a conclusion that the spatial assessment using remotely sensed data can further narrow acceptable PARs - thus reducing 440 predictive uncertainty (e.g., equifinality). 

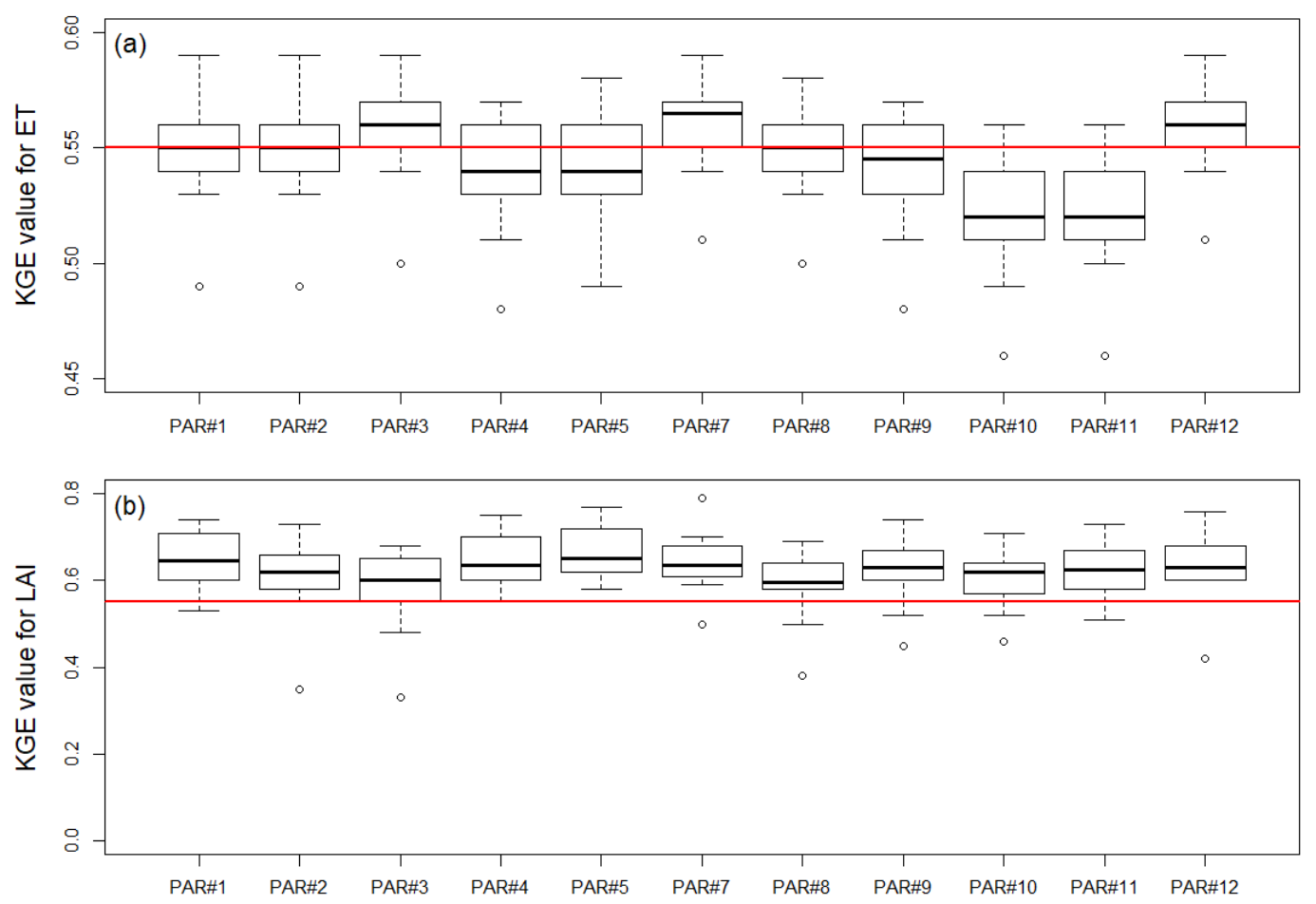

443 Fig. 5. KGE values for (a) ET and (b) LAI at the sub-watershed level. The vertical red line indicates 444 a KGE threshold value of 0.55 . KGE values of ET and LAI for individual sub-watersheds are 445 available in the supplementary material Tables S3 and S4, respectively. 

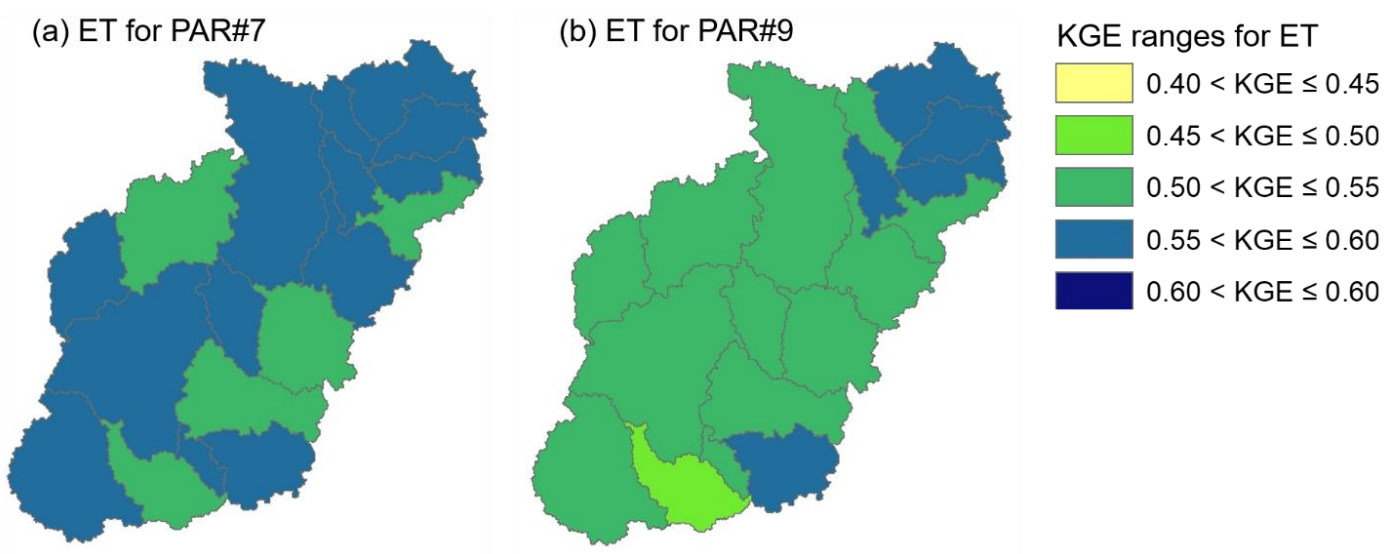

(c) LAI for PAR\#7

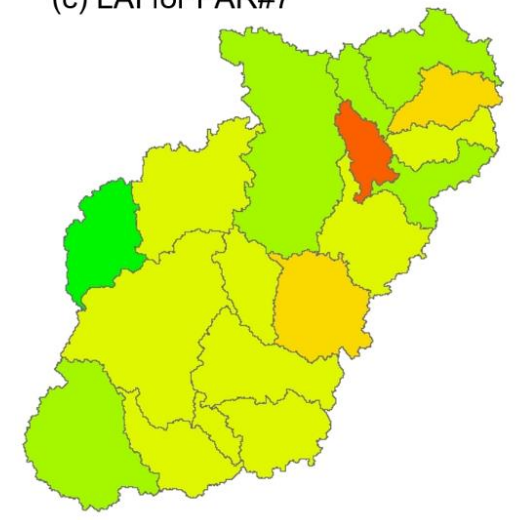

(d) LAI for PAR\#9

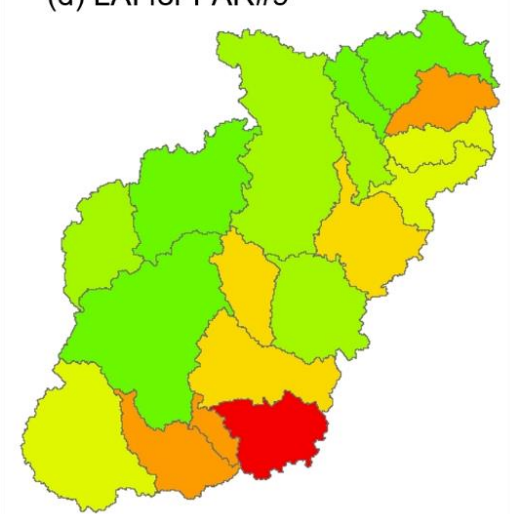

$K G E$ ranges for $\mathrm{LAI}$

$0.40<\mathrm{KGE} \leq 0.45$

$0.45<\mathrm{KGE} \leq 0.50$

$0.50<\mathrm{KGE} \leq 0.55$

$0.55<\mathrm{KGE} \leq 0.60$

$0.60<\mathrm{KGE} \leq 0.65$

$0.65<\mathrm{KGE} \leq 0.70$

$0.70<\mathrm{KGE} \leq 0.75$

$0.75<\mathrm{KGE} \leq 0.80$
447
Fig. 6. The spatial distribution of KGE values for the PAR\#7 and PAR\#9 cases at the subwatershed level for ET ( $a$ and $b$ ) and LAI (c and d).

At the sub-watershed level, approximately half of the PARs-2 were acceptable for ET while all PARs-2 met the sub-watershed-level LAI criterion. This was likely due to the spatial resolution of RS-ET and RS-LAI (Fig. 2). RS-ET with a 30-meter resolution might better represent the subwatershed-level ET, but RS-LAI with a 500-meter resolution might not well discern the the subwatershed-level LAI from the watershed-level value. 
Previous studies have illustrated that, while a spatialized parameterization requires large computational resources and long simulation times, it is useful for characterizing large watersheds (Becker et al., 2019; Rajib et al., 2018). However, relative to the spatial extent of those studies (> $\left.1670 \mathrm{~km}^{2}\right)$, the spatial extent of our study site $\left(220 \mathrm{~km}^{2}\right)$ is small, and our study focused on the use of multiple remotely sensed data to reduce predictive uncertainty. Therefore, we would argue that the lumped parameterization used in this study was sufficient to assess the prediction accuracy of the spatial distribution of ET and LAI.

\subsection{The consistency between ET and LAI at the HRU level}

Using simulations from the PARs- 2 case, an assessment was conducted to identify the PAR indicating the spatial and temporal consistencies between simulated ET and LAI for five different cropland types using the Pareto frontiers (Fig. 7). The lower values indicated a greater consistency between ET and LAI (x-axis: temporal consistency and y-axis: spatial consistency). The spatial consistency between simulated ET and LAI tended to be better than the temporal consistency between them (Fig. 7). The spatial consistency was assessed using 5-year averages of ET and LAI for individual HRUs within individual cropland types, while cropland-level daily values were used for the temporal consistency. Seasonal variations of ET and LAI were evidently observed in this region (Fig. 4 c-f). Thus, the 5-year average values used in the spatial consistency smoothened daily picky values, likely reducing inconsistent patterns between ET and LAI.

The four PARs (\#1, \#5, \#11, and \#12) were optimal for only one or two cropland types and other five PARs (\#2, \#3, \#4, \#8, and \#10) were distant from the Pareto frontiers for all cropland types (Fig. 7). Based on the assumption that ET and LAI are correlated, this HRU-level comparison 
478 likely found the PARs that improved representation of internal processes, reducing the number of 479 acceptable PARs.

480 This HRU-level assessment illustrates the capability for using multiple remotely sensed data 481 products to identify the parameter set well depicting intra-watershed processes. As discussed in 482 the introduction section, a hydrologic model is commonly calibrated using the observational data acquired at the watershed outlet, which may lead to inaccurate predictions of intra-watershed processes. Likewise, remotely sensed data struggle to provide field-level assessments due to coarse resolutions and spatial mismatch. However, after watershed-level assessment against multiple remotely sensed data, the relationships among variables calibrated at the watershed level can provide an opportunity to assess their relationships in intra-watershed processes. Furthermore, the reduction of acceptable PARs resulting from HRU-level assessment is useful when using hydrologic models for operational purposes. Modeling hydrologic models with different scenarios is commonly adopted for developing water resources management plans, and this approach often uses only one parameter set to anticipate hydrologic variables under various conditions (Gassman et al., 2014). The HRU-level assessment introduced in this study can benefit to choose the parameter set for a scenario-based modeling approach.

Previous studies modified a hydrologic model algorithm (Sharifi et al., 2016) or employed local information, e.g., annual denitrification and groundwater contribution of annual nitrate discharge at the watershed outlet, to increase model ability to simulate intra-watershed processes (Yen et al., 2014b). The two methods are not applicable for some areas with insufficient local data or limited expertise to modify model structures to reflect local characteristics. Availability of remotely sensed data is rapidly increasing, and thus the multi-level assessment shown in this study would be a possible way to overcome model predictions on intra-watershed responses. 
(a) Cropland4

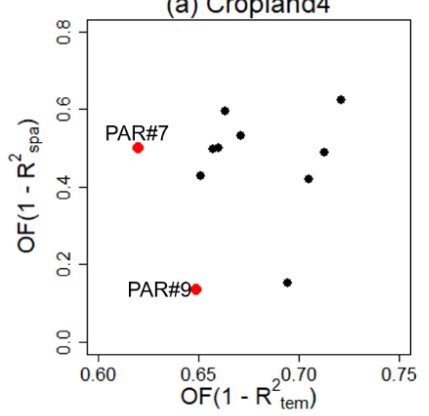

(d) Cropland7

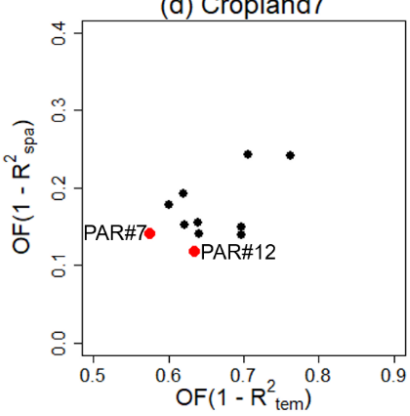

(b) Cropland5

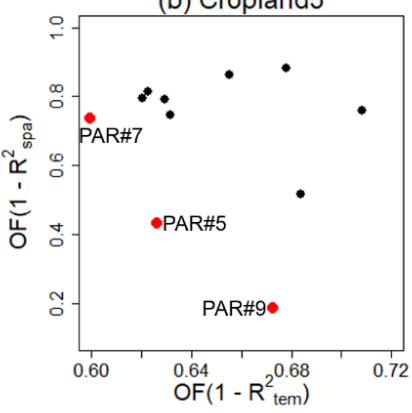

(e) Cropland8

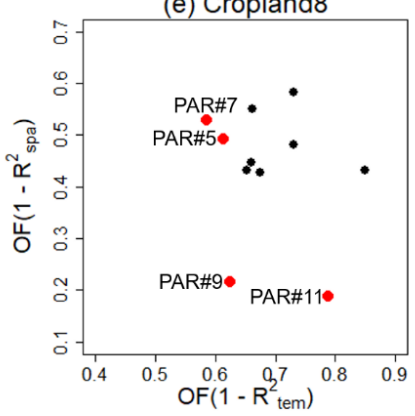

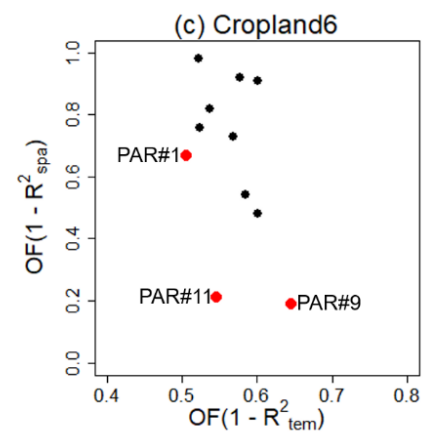

502

503

504

505

506

507

508

509

510

511

512

513

514

Fig. 7. Spatial and temporal consistency between ET and LAI for croplands 4-8. The red points indicate Pareto frontiers. The number next to the red points corresponds to the PAR number in Table $4 . R_{s p a}^{2}$ and $R_{\text {tem }}^{2}$ are $R^{2}$ values for the spatial and temporal consistency between ET and LAI, respectively. Detailed management practices for the five cropland types are shown in Table 2 .

The two PARs (\#7 and \#9) indicating superior performances at the HRU level showed similar temporal dynamics for ET and LAI (Fig. 8). However, LAI values from the PAR \#7 were greater than those from PAR \#9. The PAR \#7 case showed peak LAI values of 3.6 - 3.7 regardless of the crop rotation, but the PAR \#9 case produced peak LAI values that were 1.5 and 2.0 lower during corn and soybean growing seasons, respectively. The LAI values for corn and soybean are affected by numerous factors (e.g., climatic conditions and agricultural practices). In SWAT, the default maximum LAI values are the same for corn (LAI value: 3) and soybean (LAI value: 3 ). 
516 For the case of the Agricultural Policy/Environmental eXtender (APEX) model, corn (LAI value:

517 6) has a greater default LAI value than soybean (LAI value: 5, Williams et al., 2015). To best

518 characterize LAI dynamics in our study area, additional observational data are needed to better

519 constrain the LAI parameter.

The two PARs indicated similar ET predictions while they showed different patterns in LAI predictions. Differences in peak ET values between two PARs were 0.8 and 0.6 for corn and soybean growing seasons, respectively. It was also found that ET differences between croplands and forested areas were minimal relative to LAI differences (Fig. 9). This inconsistency of peak ET and LAI values between the two PARs was likely due to poor simulations of soil moisture conditions. In SWAT, ET is the summation of evaporation from plant canopy, transpiration, and soil evaporation. Actual transpiration is represented as the water uptake by plant root and calculated as a function of water required for plant transpiration as well as available soil water content (Neitsch et al., 2011). Therefore, the inconsistency between ET and LAI maximum values might be derived from poor soil moisture simulations. Remotely sensed soil moisture products can now be obtained from various satellite missions, the Advanced Microwave Scanning Radiometer (AMSR-E), the Advanced Scatterometer (ASCAT), the Soil Moisture and Ocean Salinity (SMOS), the Advanced Microwave Scanning Radiometer 2 (AMSR2), the Soil Moisture Active Passive 533 (SMAP), and Global Navigation Satellite System (GNSS) signals (Dorigo et al., 2015; Imaoka et 534 al., 2010; Kim et al., 2018; Kim and Lakshmi, 2018; Njoku et al., 2003; Rodriguez-Alvarez et al., 535 2009; Wagner et al., 2013). However, most of these remote sensing soil moisture data are available 536 at coarse resolutions (e.g., $25 \mathrm{~km}$ ). Future use of high-resolution soil moisture products can provide 537 additional information to the modeled spatial variations in ET and LAI. 


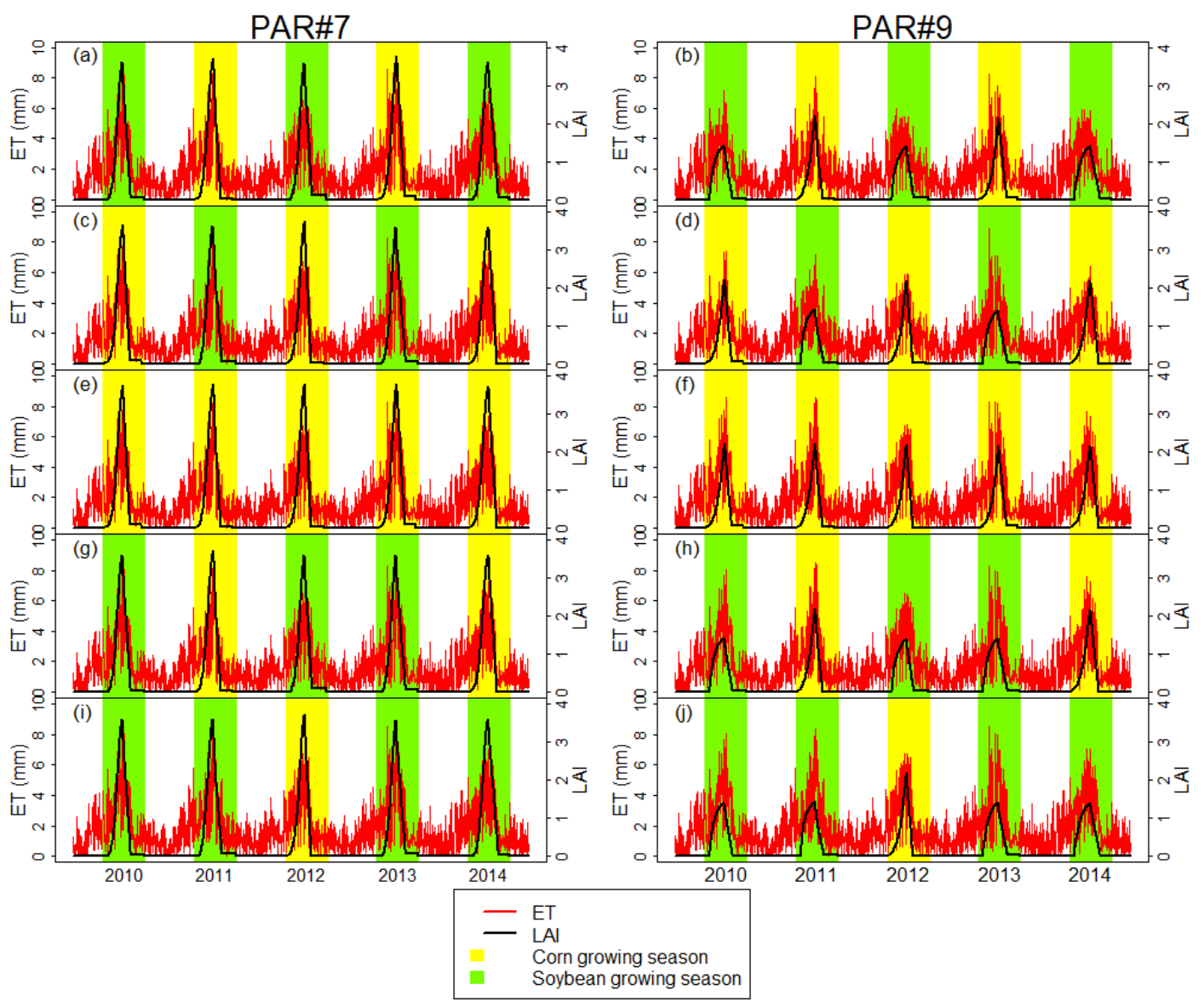

Fig. 8. Comparison of simulated ET and LAI from PAR\#7 and \#9 over five growing seasons. (a) 540 and (b) indicate cropland 4; (c) and (d) indicate cropland 5; (e) and (f) indicate cropland 6; (g) and 541 (h) indicate cropland 7; and (i) and (j) indicate cropland 8. 

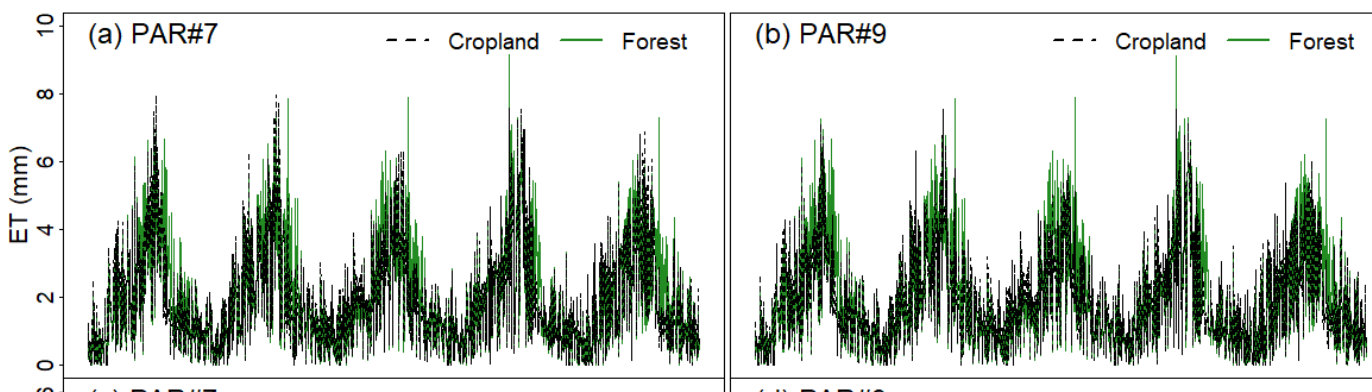

(c) PAR\#7

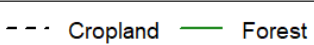

(d) PAR\#9
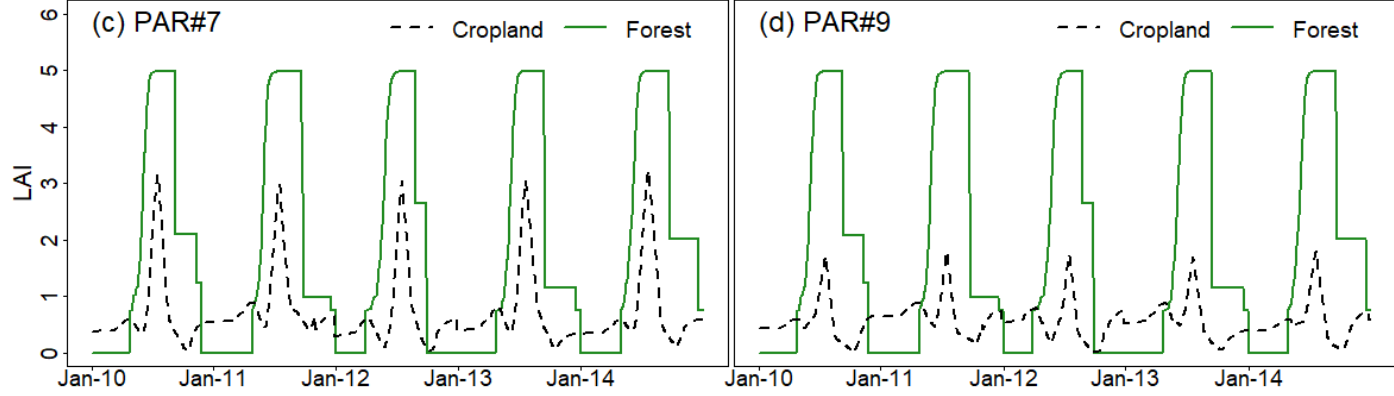

Fig. 9. Daily simulated ET and LAI for croplands and forested areas. 


\section{Summary and Conclusion}

Hydrologic modelers tackle uncertainty issues caused by incomplete model structures and a lack of observational data. To address the issue, remotely sensed data have been employed as additional contraints to enhance the prediction accuracy of hydrologic models. For example, the use of RS-ET retrivals as additional constratins has led to the substantial reduction of predictive uncertainty and the achievement of the spatial evaluation. However, vegetation parameters affecting ET dynamics are often adjusted only against RS-ET without vegetation constraints. This calibration practice may inaccurately represent vegetation impacts on ET. In this study, we employed RS-LAI as an additional constraint to contrain vegetation parameters, and we explored whether the addition of RS-LAI was beneficial to reduce parameter uncertainty. The SWAT model was calibrated against observed streamflow and RS-ET, and the calibrated model was further constrained by RS-LAI to check the number of acceptable parameter sets depending on presence or absence of RS-LAI as a constraint. We further tested how well parameter sets (acceptable for streamflow, ET, and LAI at the watershed level) depicted the spatial distribution of ET and LAI at the sub-watershed level. This finer-level evaluation was effective to constrain acceptable parameter sets. We evaluated the spatial and temporal consistencies between ET and LAI at the finest spatial level (i.e., HRU-level) with the assumption that ET and LAI are strongly correlated. Using parameter sets acceptable for ET and LAI at the watershed level, we identified the parameter sets that best represented the spatial and temporal correlation between ET and LAI for five different croplands. 
not significantly different from the one calibrated against only RS-ET. Among the 11 parameter sets, only six parameter sets represented the spatial distribution of ET and LAI at the sub-watershed level with acceptable model performances. This finding indicated that hydrologic model's equifinality is further constrained by the spatial evaluation performed in this study. Findings showed that RS-ET were the key constraint at the sub-watershed level while RS-LAI rarely limited the parameter sets. It was likely because RS-ET retrievals are obtained with a high spatial resolution (e.g., 30-meter) and did a better job of capturing spatialized characteristics relative to RS-LAI (e.g., 500-meter), therefore more efficiently constraining the acceptable parameter sets. This result suggests that the spatial resolution of remotely sensed data should be carefully selected regarding the spatial extent of the study site. At the HRU level, two parameter sets were found to satisfactorily represent the spatial and temporal consistencies between ET and LAI for five different croplands examined.

This study shows that the predictive uncertainty is not substantially affected by inclusion of RS-LAI at the watershed level, but remotely sensed data enables hydrologic modelers to conduct the spatial evaluation at finer spatial scales, which will lead to the reduction of the predictive uncertainty and improved representations of intra-watershed processes. These findings emphasized the importance of incorporating remotely sensed data as additional constraints to address uncertainty in hydrologic models, extending the usefulness of these models. 
600 Acknowledgments

601 This research was supported by the U.S. Department of Agriculture (USDA) Natural Resources

602 Conservation Service in association with the Wetland Component of the National Conservation

603 Effects Assessment Project.

604

605

Disclaimer

606 The U.S. Department of Agriculture is an equal opportunity provider and employer. Any use of

607 trade, firm, or product names is for descriptive purposes only and does not imply endorsement by

608 the U.S. Government.

609

610

611

612

613

614

615

616

617

618 
620 Andersen, J., Dybkjaer, G., Jensen, K. H., Refsgaard, J. C. and Rasmussen, K.: Use of remotely

621 sensed precipitation and leaf area index in a distributed hydrological model, J. Hydrol., 264(1-4),

622 34-50, doi:10.1016/S0022-1694(02)00046-X, 2002.

623 Anderson, M., Gao, F., Knipper, K., Hain, C., Dulaney, W., Baldocchi, D., Eichelmann, E.,

624 Hemes, K., Yang, Y., Medellin-Azuara, J. and Kustas, W.: Field-scale assessment of land and

625 water use change over the California delta using remote sensing, Remote Sens., 10(6), 889,

626 doi:10.3390/rs10060889, 2018.

627 Anderson, M. C., Norman, J. M., Diak, G. R., Kustas, W. P. and Mecikalski, J. R.: A two-source

628 time-integrated model for estimating surface fluxes using thermal infrared remote sensing,

629 Remote Sens. Environ., 60(2), 195-216, doi:10.1016/S0034-4257(96)00215-5, 1997.

630 Anderson, M. C., Norman, J. M., Mecikalski, J. R., Torn, R. D., Kustas, W. P. and Basara, J. B.:

631 A multiscale remote sensing model for disaggregating regional fluxes to micrometeorological

632 scales, J. Hydrometeorol., 5(2), 343-363, doi:10.1175/1525-

633 7541(2004)005<0343:AMRSMF>2.0.CO;2, 2004.

634 Anderson, M. C., Norman, J. M., Mecikalski, J. R., Otkin, J. A. and Kustas, W. P.: A

635 climatological study of evapotranspiration and moisture stress across the continental United

636 States based on thermal remote sensing: 1. Model formulation, J. Geophys. Res. Atmos., 112,

637 D10117, doi:10.1029/2006JD007506, 2007.

638 Arnold, J. G., Moriasi, D. N., Gassman, P. W., Abbaspour, K. C., White, M. J., Srinivasan, R.,

639 Santhi, C., Harmel, R. D., Van Griensven, A., Van Liew, M. W., Kannan, N. and Jha, M. K.:

640 SWAT: Model use, calibration, and validation, Trans. ASABE, 55(4), 1491-1508, 2012. 
641 Arnold, J. G., Youssef, M. A., Yen, H., White, M. J., Sheshukov, A. Y., Sadeghi, A. M., Moriasi, 642 D. N., Steiner, J. L., Amatya, D. M., Skaggs, R. W., Haney, E. B., Jeong, J., Arabi, M. and

643 Gowda, P. H.: Hydrological processes and model representation: Impact of soft data on 644 calibration, Trans. ASABE, 58(6), 1637-1660, doi:10.13031/trans.58.10726, 2015.

Baffaut, C., Baker, J. M., Biederman, J. A., Bosch, D. D., Brooks, E. S., Buda, A. R., Demaria, E. M., Elias, E. H., Flerchinger, G. N., Goodrich, D. C., Hamilton, S. K., Hardegree, S. P., 647 Harmel, R. D., Hoover, D. L., King, K. W., Kleinman, P. J., Liebig, M. A., McCarty, G. W., 648 Moglen, G. E., Moorman, T. B., Moriasi, D. N., Okalebo, J., Pierson, F. B., Russell, E. S., 649 Saliendra, N. Z., Saha, A. K., Smith, D. R. and Yasarer, L. M. W.: Comparative analysis of water 650 budgets across the U.S. long-term agroecosystem research network, J. Hydrol., 588, 125021, 651 doi:10.1016/j.jhydrol.2020.125021, 2020.

652 Becker, R., Koppa, A., Schulz, S., Usman, M., aus der Beek, T. and Schüth, C.: Spatially 653 distributed model calibration of a highly managed hydrological system using remote sensing654 derived ET data, J. Hydrol., 577, 123944, doi:10.1016/j.jhydrol.2019.123944, 2019. Beven, K.: A manifesto for the equifinality thesis, in Journal of Hydrology, pp. 18-36., 2006. evapotranspiration based on leaf area index, precipitation and pan evaporation: A case study of Poyang Lake watershed, China, Ecohydrol. Hydrobiol., 19(1), 83-92, doi:10.1016/j.ecohyd.2018.03.005, 2019.

660 Cammalleri, C., Anderson, M. C., Gao, F., Hain, C. R. and Kustas, W. P.: A data fusion 661 approach for mapping daily evapotranspiration at field scale, Water Resour. Res., 49(8), 4672662 4686, doi:10.1002/wrcr.20349, 2013. 
663 Cammalleri, C., Anderson, M. C., Gao, F., Hain, C. R. and Kustas, W. P.: Mapping daily

664 evapotranspiration at field scales over rainfed and irrigated agricultural areas using remote

665 sensing data fusion, Agric. For. Meteorol., 186, 1-11, doi:10.1016/j.agrformet.2013.11.001,

6662014.

667 Chen, F., Crow, W. T., Starks, P. J. and Moriasi, D. N.: Improving hydrologic predictions of a

668 catchment model via assimilation of surface soil moisture, Adv. Water Resour., 34(4), 526-536,

669 doi:10.1016/j.advwatres.2011.01.011, 2011.

670 Chen, Y., Marek, G. W., Marek, T. H., Brauer, D. K. and Srinivasan, R.: Assessing the efficacy

671 of the SWAT auto-irrigation function to simulate irrigation, evapotranspiration, and crop

672 response to management strategies of the texas high plains, Water (Switzerland), 9(7), 509,

673 doi:10.3390/w9070509, 2017.

674 Dorigo, W. A., Gruber, A., De Jeu, R. A. M., Wagner, W., Stacke, T., Loew, A., Albergel, C.,

675 Brocca, L., Chung, D., Parinussa, R. M. and Kidd, R.: Evaluation of the ESA CCI soil moisture

676 product using ground-based observations, Remote Sens. Environ., 162, 380-395,

677 doi:10.1016/j.rse.2014.07.023, 2015.

678 Duriancik, L. F., Bucks, D., Dobrowolski, J. P., Drewes, T., Eckles, S. D., Jolley, L., Kellogg, R.

679 L., Lund, D., Makuch, J. R., O’Neill, M. P., Rewa, C. A., Walbridge, M. R., Parry, R. and Weltz,

680 M. A.: The first five years of the: Conservation effects assessment project, J. Soil Water

681 Conserv., 63(6), 185A-188A, doi:10.2489/jswC.63.6.185A, 2008.

682 Fisher, T. R., Jordan, T. E., Staver, K. W., Gustafson, A. B., Koskelo, A. I., Fox, R. J., Sutton, A.

683 J., Kana, T., Beckert, K. A., Stone, J. P., McCarty, G. and Lang, M.: The choptank basin in 
transition: Intensifying agriculture, slow urbanization, and estuarine eutrophication, in Coastal

Lagoons: Critical Habitats of Environmental Change., 2010.

686 Gassman, P. W., Sadeghi, A. M. and Srinivasan, R.: Applications of the SWAT Model Special

687 Section: Overview and Insights, J. Environ. Qual., 43(1), 1-8, doi:10.2134/jeq2013.11.0466,

6882014.

689 Gigante, V., Iacobellis, V., Manfreda, S., Milella, P. and Portoghese, I.: Influences of leaf area 690 index estimations on water balance modeling in a mediterranean semi-arid basin, Nat. Hazards

691 Earth Syst. Sci., 9(3), 979-991, doi:10.5194/nhess-9-979-2009, 2009.

692 Gupta, H. V., Kling, H., Yilmaz, K. K. and Martinez, G. F.: Decomposition of the mean squared error and NSE performance criteria: Implications for improving hydrological modelling, J.

Hydrol., 377(1-2), 80-91, doi:10.1016/j.jhydrol.2009.08.003, 2009.

695

696

697

698

699

700

701

702

703

704

Ha, L. T., Bastiaanssen, W. G. M., van Griensven, A., van Dijk, A. I. J. M. and Senay, G. B.: Calibration of spatially distributed hydrological processes and model parameters in SWAT using remote sensing data and an auto-calibration procedure: A case study in a Vietnamese river basin, Water (Switzerland), 10(2), 212, doi:10.3390/w10020212, 2018.

Hain, C. R., Crow, W. T., Anderson, M. C. and Tugrul Yilmaz, M.: Diagnosing neglected soil moisture source-sink processes via a thermal infrared-based two-source energy balance model, J. Hydrometeorol., 16, 1070-1086, doi:10.1175/JHM-D-14-0017.1, 2015.

Herman, M. R., Nejadhashemi, A. P., Abouali, M., Hernandez-Suarez, J. S., Daneshvar, F., Zhang, Z., Anderson, M. C., Sadeghi, A. M., Hain, C. R. and Sharifi, A.: Evaluating the role of evapotranspiration remote sensing data in improving hydrological modeling predictability, J. Hydrol., 556, 39-49, doi:10.1016/j.jhydrol.2017.11.009, 2018. 
706 Hively, W. D., Lee, S., Sadeghi, A. M., McCarty, G. W., Lamb, B. T., Soroka, A., Keppler, J.,

707 Yeo, I. Y. and Moglen, G. E.: Estimating the effect of winter cover crops on nitrogen leaching

708 using cost-share enrollment data, satellite remote sensing, and Soil and Water Assessment Tool

709 (SWAT) modeling, J. Soil Water Conserv., 75(3), 362-375, doi:10.2489/JSWC.75.3.362, 2020.

710 Imaoka, K., Kachi, M., Kasahara, M., Ito, N., Nakagawa, K. and Oki, T.: Instrument

711 performance and calibration of AMSR-E and AMSR2, Int. Arch. Photogramm. Remote Sens.

712 Spat. Inf. Sci. - ISPRS Arch., 38(8), 13-18, 2010.

713 Jiang, D. and Wang, K.: The role of satellite-based remote sensing in improving simulated

714 streamflow: A review, Water (Switzerland), 1615, doi:10.3390/w11081615, 2019.

715 Julich, S., Breuer, L. and Frede, H. G.: Integrating heterogeneous landscape characteristics into

716 watershed scale modelling, Adv. Geosci., 31, 31-38, doi:10.5194/adgeo-31-31-2012, 2012.

717 Kim, H. and Lakshmi, V.: Use of Cyclone Global Navigation Satellite System (CyGNSS)

718 Observations for Estimation of Soil Moisture, Geophys. Res. Lett., 45(16), 8272-8282,

719 doi:10.1029/2018GL078923, 2018.

720 Kim, H., Parinussa, R., Konings, A. G., Wagner, W., Cosh, M. H., Lakshmi, V., Zohaib, M. and

721 Choi, M.: Global-scale assessment and combination of SMAP with ASCAT (active) and AMSR2

722 (passive) soil moisture products, Remote Sens. Environ., 204, 260-275,

723 doi:10.1016/j.rse.2017.10.026, 2018.

724 Lee, S., Yeo, I.-Y., Sadeghi, A. M., McCarty, G. W., Hively, W. D. and Lang, M. W.: Impacts of

725 watershed characteristics and crop rotations on winter cover crop nitrate-nitrogen uptake

726 capacity within agricultural watersheds in the Chesapeake Bay region, PLoS One, 11(6),

727 e0157637, doi:10.1371/journal.pone.0157637, 2016. 
728 Lee, S., Yeo, I.-Y., Lang, M. W., McCarty, G. W., Sadeghi, A. M., Sharifi, A., Jin, H. and Liu,

729 Y.: Improving the catchment scale wetland modeling using remotely sensed data, Environ.

730 Model. Softw., 122, 104069, doi:10.1016/j.envsoft.2017.11.001, 2019.

731 McCarty, G. W., McConnell, L. L., Hapeman, C. J., Sadeghi, A., Graff, C., Hively, W. D., Lang,

732 M. W., Fisher, T. R., Jordan, T., Rice, C. P., Codling, E. E., Whitall, D., Lynn, A., Keppler, J.

733 and Fogel, M. L.: Water quality and conservation practice effects in the Choptank River

734 watershed, J. Soil Water Conserv., 63(6), 461-474, doi:10.2489/jswc.63.6.461, 2008.

735 McKay, M. D., Beckman, R. J. and Conover, W. J.: A comparison of three methods for selecting

736 values of input variables in the analysis of output from a computer code, Technometrics, 21(2),

737 239-245, doi:10.1080/00401706.2000.10485979, 2000.

738 Myneni, R. B., Hoffman, S., Knyazikhin, Y., Privette, J. L., Glassy, J., Tian, Y., Wang, Y., Song,

739 X., Zhang, Y., Smith, G. R., Lotsch, A., Friedl, M., Morisette, J. T., Votava, P., Nemani, R. R.

740 and Running, S. W.: Global products of vegetation leaf area and fraction absorbed PAR from

741 year one of MODIS data, Remote Sens. Environ., 83, 214-231, doi:10.1016/S0034-

742 4257(02)00074-3, 2002.

743 Neitsch, S. ., Arnold, J. ., Kiniry, J. . and Williams, J. .: Soil \& Water Assessment Tool

744 Theoretical Documentation Version 2009., 2011.

745 Njoku, E. G., Jackson, T. J., Lakshmi, V., Chan, T. K. and Nghiem, S. V.: Soil moisture retrieval

746 from AMSR-E, IEEE Trans. Geosci. Remote Sens., 41(2), 215-229,

747 doi:10.1109/TGRS.2002.808243, 2003. 
748 Norman, J. M., Kustas, W. P. and Humes, K. S.: Source approach for estimating soil and

749 vegetation energy fluxes in observations of directional radiometric surface temperature, Agric.

750 For. Meteorol., 77, 263-293, doi:10.1016/0168-1923(95)02265-Y, 1995.

751 Odusanya, A. E., Mehdi, B., Schürz, C., Oke, A. O., Awokola, O. S., Awomeso, J. A.,

752 Adejuwon, J. O. and Schulz, K.: Multi-site calibration and validation of SWAT with satellite-

753 based evapotranspiration in a data-sparse catchment in southwestern Nigeria, Hydrol. Earth Syst.

754 Sci., 23(2), 1113-1144, doi:10.5194/hess-23-1113-2019, 2019.

755 Parajuli, P. B., Jayakody, P., Sassenrath, G. F., Ouyang, Y. and Pote, J. W.: Assessing the

756 impacts of crop-rotation and tillage on crop yields and sediment yield using a modeling

757 approach, Agric. Water Manag., 119, 32-42, doi:10.1016/j.agwat.2012.12.010, 2013.

758 Parajuli, P. B., Jayakody, P. and Ouyang, Y.: Evaluation of Using Remote Sensing

759 Evapotranspiration Data in SWAT, Water Resour. Manag., 32(3), 985-996, doi:10.1007/s11269-

$760 \quad 017-1850-\mathrm{z}, 2018$.

761 Poméon, T., Diekkrüger, B., Springer, A., Kusche, J. and Eicker, A.: Multi-objective validation

762 of SWAT for sparsely-gaugedWest African river basins - A remote sensing approach, Water

763 (Switzerland), 10(4), 451, doi:10.3390/w10040451, 2018.

764 Rajib, A., Evenson, G. R., Golden, H. E. and Lane, C. R.: Hydrologic model predictability

765 improves with spatially explicit calibration using remotely sensed evapotranspiration and

766 biophysical parameters, J. Hydrol., 567, 668-683, doi:10.1016/j.jhydrol.2018.10.024, 2018.

767 Rodriguez-Alvarez, N., Bosch-Lluis, X., Camps, A., Vall-Llossera, M., Valencia, E., Marchan-

768 Hernandez, J. F. and Ramos-Perez, I.: Soil moisture retrieval using GNSS-R techniques: 
769 Experimental results over a bare soil field, IEEE Trans. Geosci. Remote Sens., 47(11), 3616-

$770 \quad 3624$, doi:10.1109/TGRS.2009.2030672, 2009.

771 Roocks, P.: Computing pareto frontiers and database preferences with the rPref package, R J.,

772 doi:10.32614/rj-2016-054, 2016.

773 Schlesinger, W. H. and Jasechko, S.: Transpiration in the global water cycle, Agric. For.

774 Meteorol., 189(115), 117, doi:10.1016/j.agrformet.2014.01.011, 2014.

775 Seibert, J. and McDonnell, J. J.: On the dialog between experimentalist and modeler in

776 catchment hydrology: Use of soft data for multicriteria model calibration, Water Resour. Res.,

777 38(11), 1241, doi:10.1029/2001wr000978, 2002.

778 Sexton, A. M., Sadeghi, A. M., Zhang, X., Srinivasan, R. and Shirmohammadi, A.: Using

779 NEXRAD and rain gauge precipitation data for hydrologic calibration of SWAT in a

780 northeastern watershed, Trans. ASABE, 53(5), 1501-1510, doi:10.13031/2013.34900, 2010.

781 Sharifi, A., Lang, M. W., McCarty, G. W., Sadeghi, A. M., Lee, S., Yen, H., Rabenhorst, M. C.,

782 Jeong, J. and Yeo, I.-Y.: Improving model prediction reliability through enhanced representation

783 of wetland soil processes and constrained model auto calibration - A paired watershed study, J.

784 Hydrol., 541, 1088-1103, doi:10.1016/j.jhydrol.2016.08.022, 2016.

785 Stisen, S., Jensen, K. H., Sandholt, I. and Grimes, D. I. F.: A remote sensing driven distributed

786 hydrological model of the Senegal River basin, J. Hydrol., 354(1-4), 131-148,

787 doi:10.1016/j.jhydrol.2008.03.006, 2008. 
788 Strauch, M. and Volk, M.: SWAT plant growth modification for improved modeling of perennial

789 vegetation in the tropics, Ecol. Modell., 269, 98-112, doi:10.1016/j.ecolmodel.2013.08.013,

7902013.

791 Sun, L., Anderson, M. C., Gao, F., Hain, C., Alfieri, J. G., Sharifi, A., McCarty, G. W., Yang,

792 Y., Yang, Y., Kustas, W. P. and McKee, L.: Investigating water use over the Choptank River

793 Watershed using a multisatellite data fusion approach, Water Resour. Res., 53, 5298-5319,

794 doi:10.1002/2017WR020700, 2017.

795 Vaché, K. B. and McDonnell, J. J.: A process-based rejectionist framework for evaluating

796 catchment runoff model structure, Water Resour. Res., 42(2), doi:10.1029/2005WR004247,

7972006.

798 Wagner, W., Hahn, S., Kidd, R., Melzer, T., Bartalis, Z., Hasenauer, S., Figa-Saldaña, J., De

799 Rosnay, P., Jann, A., Schneider, S., Komma, J., Kubu, G., Brugger, K., Aubrecht, C., Züger, J.,

800 Gangkofner, U., Kienberger, S., Brocca, L., Wang, Y., Blöschl, G., Eitzinger, J., Steinnocher, K.,

801 Zeil, P. and Rubel, F.: The ASCAT soil moisture product: A review of its specifications,

802 validation results, and emerging applications, Meteorol. Zeitschrift, 22(1), 5-33,

803 doi:10.1127/0941-2948/2013/0399, 2013.

804 Wallace, C. W., Flanagan, D. C. and Engel, B. A.: Evaluating the effects ofwatershed size on

805 SWAT calibration, Water (Switzerland), 10(7), 898, doi:10.3390/w10070898, 2018.

806 Wambura, F. J., Dietrich, O. and Lischeid, G.: Improving a distributed hydrological model using 807 evapotranspiration-related boundary conditions as additional constraints in a data-scarce river 808 basin, Hydrol. Process., 32(6), 759-775, doi:10.1002/hyp.11453, 2018. 
809 Wang, K., Dickinson, R. E., Wild, M. and Liang, S.: Evidence for decadal variation in global

810 terrestrial evapotranspiration between 1982 and 2002: 1. Model development, J. Geophys. Res.

811 Atmos., 115(D20), doi:10.1029/2009JD013671, 2010.

812 Winchell, M., Srinivasan, R., Di Luzio, M. and Arnold, J.: ArcSWAT interface for SWAT 2005,

813 User's Guid., 2007.

814 Wolman, M. G.: Water for Maryland's Future: What We Must Do Today, Baltimore, Md., 2008.

$815 \mathrm{Xu}, \mathrm{X} ., \mathrm{Li}, \mathrm{J}$. and Tolson, B. A.: Progress in integrating remote sensing data and hydrologic

816 modeling, Prog. Phys. Geogr., 38(4), 464-498, doi:10.1177/0309133314536583, 2014.

817 Yan, H., Wang, S. Q., Billesbach, D., Oechel, W., Zhang, J. H., Meyers, T., Martin, T. A.,

818 Matamala, R., Baldocchi, D., Bohrer, G., Dragoni, D. and Scott, R.: Global estimation of

819 evapotranspiration using a leaf area index-based surface energy and water balance model,

820 Remote Sens. Environ., 124, 581-595, doi:10.1016/j.rse.2012.06.004, 2012.

821 Yen, H., Wang, X., Fontane, D. G., Harmel, R. D. and Arabi, M.: A framework for propagation

822 of uncertainty contributed by parameterization, input data, model structure, and

823 calibration/validation data in watershed modeling, Environ. Model. Softw., 43(5), 1601-1613,

824 doi:10.1016/j.envsoft.2014.01.004, 2014a.

825 Yen, H., Bailey, R. T., Arabi, M., Ahmadi, M., White, M. J. and Arnold, J. G.: The Role of

826 Interior Watershed Processes in Improving Parameter Estimation and Performance of Watershed

827 Models, J. Environ. Qual., 43(5), 1601-1613, doi:10.2134/jeq2013.03.0110, 2014b. 
828 Yen, H., White, M. J., Ascough, J. C., Smith, D. R. and Arnold, J. G.: Augmenting Watershed

829 Model Calibration with Incorporation of Ancillary Data Sources and Qualitative Soft Data

830 Sources, J. Am. Water Resour. Assoc., 52(3), 788-798, doi:10.1111/1752-1688.12428, 2016.

831 Yeo, I.-Y., Lee, S., Sadeghi, A. M., Beeson, P. C., Hively, W. D., McCarty, G. W. and Lang, M.

832 W.: Assessing winter cover crop nutrient uptake efficiency using a water quality simulation

833 model, Hydrol. Earth Syst. Sci., 18, 5239-5253, doi:10.5194/hess-18-5239-2014, 2014.

834 Yeo, I.-Y., Lee, S., Lang, M. W., Yetemen, O., McCarty, G. W., Sadeghi, A. M. and Evenson,

835 G.: Mapping landscape-level hydrological connectivity of headwater wetlands to downstream

836 waters: A catchment modeling approach - Part 2, Sci. Total Environ., 653, 1557 - 1570,

837 doi:10.1016/j.scitotenv.2018.11.237, 2019.

838 Zambrano, M. B.: Package "hydroGOF": Goodness-of-Fit Functions for Comparison of

839 Simulated and Observed Hydrological Time Series, R Packag. version 0.3-8., 2017. 